\title{
DESARROLLO DE LA PROVINCIA ECLESIÁSTICA DE LIMA 1599-1800, FOCALIZADO EN LA RELACIÓN METRÓPOLIS Y DIÓCESIS PERIFÉRICAS, EN LAS RELACIONES DE VISITA AD LIMINA APOSTOLORUM
}

\author{
POR \\ MisAel CAMUS IBACACHE ${ }^{1}$ \\ Universidad de Tarapacá \\ Departamento de Ciencias Históricas y Geográficas \\ Arica-Chile
}

\begin{abstract}
RESUMEN
La investigación ofrece una visión sobre el desarrollo de la provincia eclesiástica de Lima, subrayando las diócesis periféricas, esto es, Quito, Arequipa, Santiago de Chile. El estudio demuestra como el atributo de la autonomía y el carácter colegial del perfil del obispo, permitieron que las diócesis periféricas de esta provincia eclesiástica resolvieran los desafíos de la maduración y consolidación de las estructuras eclesiales con mejores eficiencias. Estos procesos se fortalecieron con la recepción del Concilio de Trento en las Leyes Patronales, en especial aquellas de reforma, como la residencia y la visita pastoral del obispo, sea la fundación de seminarios como la celebración de sínodos diocesanos o concilios provinciales. Estos aspectos han sido individualizados en las relaciones de la visita ad limina Apostolorum, que los obispos enviaron a Roma, cada diez años, según la norma creada por Sixto V en 1585.
\end{abstract}

PALABRAS CLAVE: obispos; visitas canónicas; visita ad limina; clero secular y regular; parroquias y doctrinas; monasterios femeninos; Concilio de Trento; concilio provincial; sínodo.

\section{THE DEVELOPMENT OF THE ECCLESIASTICAL PROVINCE OF LIMA 1599-1800: AN ANALYSIS FOCUSED ON THE RELATION OF THE METROPOLIS AND PERIPHERAL DIOCESES, BASED ON THE REPORTS OF VISITA AD LIMINA APOSTOLORUM}

\begin{abstract}
The research offers an insight into the development of the Ecclesiastical Province of Lima, highlighting the peripheral dioceses, namely Quito, Arequipa, and Santiago de Chile. The study shows how the attributes of autonomy and the collegial character of the bishop's profile allowed the peripheral dioceses of this Ecclesiastical Province to solve the challenges of maturing and consolidating ecclesial structures more efficiently. These processes were strengthened with the influence of the Council of Trent in the patronage laws, especially those related to reforms, such as the residence and pastoral visit of the bishop, the foundation of seminaries and the celebration of diocesan synods or provincial councils. These aspects have been found analyzing the reports of the Visita ad Limina Apostolorum that bishops sent to Rome, every ten years, according to the rule promulgated by Sixtus V in 1585.
\end{abstract}

KEY WORDS: bishops; canonical visits; visita ad limina; secular and regular clergy; parishes and doctrines; female monasteries; Council of Trent; provincial council; synod.

Cómo CITAR ESTE ARTículo / CITATION: Camus Ibacache, Misael. 2019. «Desarrollo de la provincia eclesiástica de Lima 15991800, focalizado en la relación metrópolis y diócesis periféricas, en las Relaciones de visita ad limina Apostolorum». Hispania Sacra 71, 144: 503-520. https://doi.org/10.3989/hs.2019.036

Recibido/Received 26-07-2017

Aceptado/Accepted 20-02-2018

1 misaelhcamus@gmail.com / ORCID iD: https://orcid.org/0000-0002-6817-2955 
El estudio sobre la práctica de la visita ad limina desde América Latina, período hispánico, es incipiente como línea de investigación. ${ }^{2}$ Este trabajo estructurado desde un conjunto documental, en su mayor parte inédito, ofrece aportes a la historiografía eclesial latinoamericana, a saber: primero, presenta en forma articulada la valorización de fuentes conservadas en el Archivo Secreto Vaticano, sobre la práctica del cumplimiento de la visita ad limina Apostolorum (en adelante, visita ad limina), de los obispos de la Provincia Eclesiástica de Lima, con algunos antecedentes de la Provincia de Sucre/La Plata o Charcas; segundo, aporta al conocimiento de la práctica de visita ad limina, demostrando que los obispos conocieron de la obligación de cumplir con el precepto promulgado por Sixto $V$ en 1585; tercero, a través del seguimiento de la Relación diocesana sobre el estado de la iglesia (en adelante, Relación) se describen aspectos del perfil pastoral de los prelados, en particular, la recepción del Concilio de Trento, en clave de misión; cuarto, constatar para la comprensión de estas Iglesias cómo: la autonomía del obispo y el vínculo fraternal -colegiado- entre ellos, se remonta tempranamente a la fase de instalación de la Iglesia, y que la base jurídica de las leyes patronales fueron el instrumento de recepción del Concilio de Trento, y de ello se deriva el carácter pastoral de las mismas.

A los aportes antes descritos del estudio ofrece un plus articulador en el análisis, que será individualizar qué factores permitieron el desarrollo de las Iglesias periféricas de la provincia, que observan mayor frecuencia en el precepto de visita ad limina, esto es, Quito, Arequipa y Santiago de Chile. Estas Iglesias están consolidadas a fines del s. XVIII.

Extrapolando el trabajo de Fernand Braudel, El Mediterráneo y el mundo mediterráneo en la época de Felipe $I I,{ }^{3}$ en el que el autor centra en la geografía física y la geografía humana, como los factores claves de incidencia, tanto en el desarrollo económico como político de las comunidades; este trabajo plantea que a los factores geográficos más los atributos de la constitución eclesial, fueron los que se activaron, en el contexto de lejanía de las sufragáneas sea de Roma sea del centro metropolitano, un desarrollo sostenido y autónomo. El principio de la autoconciencia del sentido universal del cristianismo se ha desarrollado en el accionar equilibrado entre dos institutos, aquel de Pedro y aquel de los Apóstoles. La manifestación concreta de esos atributos se expresa en la autonomía y la colegialidad de los apóstoles, en materia de gestión y conducción de la comunidad y en la administración de la justicia a sus miembros, sostenida por una sólida vinculación con el centro.

El estudio releva que estos atributos - autonomía y colegialidad- de la constitución eclesiástica católica, se activaron de forma natural en los obispos latinoamericanos, aun cuando estaban - aparentemente- condicionados por las leyes patronales.

2 En octubre de 1993 l'École francaise de Rome et l'École des hautes études en sciencies sociales, organizó un Coloquio (4 y 5 octubre de 1993) sobre esta línea de investigación. Las actas del coloquio fueron publicadas por la Collection de L'École Francaise de Rome-293. 2002. Les Chemins de Rome. Les Visites ad limina à l'époque moderne dans l'Éurope Meridionale et le Monde Hispano-Americain. Editor Philippe Boutry et Bernard Vincent. Rome-293: 275 págs. En tal coloquio Cárcel Ortíz, María. 2002. La Visita ad Limina: Propuesta de Edición. Rome-293: 5-37, ofrece información del estado de la historiografía tanto para España como América Latina.

3 Braudel 1981: 472.
El trabajo se articula en varios apartados, que son: la práctica de visita ad limina en la provincia limeña y en la provincia - desmembrada- de Sucre; desarrollo consolidado de la diócesis metropolitana en el marco de procedimientos y contenidos en las Relaciones; estados de las diócesis sufragáneas periféricas, a través del estudio de las Relaciones; y culmina con un análisis conclusivo.

\section{LA PRÁCTICA DE LA VISITA AD LIMINA EN LAS PROVINCIAS DE LIMA Y SUCRE}

\subsection{Las fuentes documentales desde una perspectiva estadística}

El apartado se concentra en las diócesis sufragáneas de Lima y de Sucre, teniendo como referencia las diócesis indicadas en la Relación de la visita ad limina de 1599/1603 del arzobispo Mogrovejo.

Las diócesis del arzobispado de Sucre serán una referencia indirecta, porque eran parte de Lima hasta 1609 . Al incorporarlas interesa en cuanto que aportan una visión panorámica del desarrollo de la Iglesia en un escenario geográfico tan complejo como es el cono sur del continente de América Latina. Al ver las dos arquidiócesis en su conjunto, esto es, desde Quito por el norte y Concepción de Chile por el suroeste y desde La Paz hasta Asunción por el sur se tiene una comprensión más aguda del impacto de la geografía. El orden de la ubicación en la nómina está dado por el número de visita ad limina registradas.

Para introducir este apartado, en la Tabla 1 se expone un inventario de la visita ad limina de las diócesis que

TABLA 1

Frecuencia de la práctica de visita ad limina de las Provincias de Lima y Sucre

\begin{tabular}{|c|c|c|c|c|}
\hline $\begin{array}{l}\text { Provincia y } \\
\text { Diócesis }\end{array}$ & $\begin{array}{l}\text { Siglo } \\
\text { XVII }\end{array}$ & $\begin{array}{l}\text { Siglo } \\
\text { XVIII }\end{array}$ & Total & Comentario \\
\hline \multicolumn{5}{|l|}{ Provincia de Lima } \\
\hline Lima & 12 & $1(1721)$ & 13 & Información relevante. \\
\hline Quito & 8 & $5(1751)$ & 13 & $\begin{array}{l}\text { Se observa crecimiento y } \\
\text { autonomía. }\end{array}$ \\
\hline Santiago de Chile & 4 & $7(1773)$ & 11 & $\begin{array}{l}\text { Relaciones fines s. XVIII } \\
\text { reflejan estado de las } \\
\text { diócesis. }\end{array}$ \\
\hline Arequipa & 5 & $4(1759)$ & 9 & Incipiente desarrollo. \\
\hline Panamá & 3 & $3(1770)$ & 6 & Expuesta al medio. \\
\hline Concepción Chile & 1 & $5(1769)$ & 6 & $\begin{array}{l}\text { Incipiente imagen de la } \\
\text { Iglesia. }\end{array}$ \\
\hline Truxillos & 2 & $2(1744)$ & 4 & Información muy limitada. \\
\hline Cusco & 2 & $1(1705)$ & 3 & Escasa información. \\
\hline Guamanga & 2 & $1(1731)$ & 3 & Escaso desarrollo. \\
\hline Sub total & 39 & 29 & 68 & \\
\hline \multicolumn{5}{|l|}{ Provincia de Sucre } \\
\hline Tucumán & 5 & $4(1764)$ & 9 & $\begin{array}{l}\text { Inestabilidad sede episcopal } \\
\text { y misiones. }\end{array}$ \\
\hline Sucre & 4 & $3(1772)$ & 7 & Incipiente desarrollo. \\
\hline B. Aires & 1 & $3(1805)$ & 4 & Escasa información. \\
\hline Santa Cruz & 2 & $2(1748)$ & 4 & Escasos datos. \\
\hline Asunción & 2 & $1(1786)$ & 3 & Impacto medio geográfico. \\
\hline La Paz & 1 & 0 & 1 & Impacto medio geográfico. \\
\hline Sub total & 15 & 13 & 28 & \\
\hline Total & 54 & 42 & 96 & \\
\hline
\end{tabular}


abarcaron ambos arzobispados. En la columna siglo XVIII, se anota entre paréntesis el año del último precepto cumplido, lo cual ayudará al análisis comparado.

Un razonamiento teórico sobre la frecuencia de la práctica de visita ad limina, para poner en acción el método: para las Iglesias de ultramar la norma mandaba que la visita se cumpliese cada diez años; por tanto, en doscientos años se debieron ejecutar 20 visitas por diócesis; y en las 15 diócesis registradas, debieran arrojar 300 visitas.

\subsection{Observaciones generales a la práctica visita ad limina}

- Ninguna diócesis cumplió con la visita ad limina cada diez años, en el período de 200 años.

- La frecuencia más alta en el s. XVII la cumplió Lima en $100 \%$; Quito, en $80 \%$; Tucumán en $50 \%$; Sucre y Arequipa, cerca del $50 \%$; y Santiago de Chile el $40 \%$.

- La frecuencia de la sede de Lima cayó en el s. XVIII: alcanzó un $10 \%$; Quito y Tucumán un $40 \%$; Santiago la incrementó a un 70 \%; Concepción de Chile surge con un $60 \%$.

- La frecuencia en el arzobispado de Sucre es baja y sin diferencia entre los dos siglos. Extremadamente delicado son los datos de Asunción y La Paz.

- El excepcional comportamiento de Tucumán y con regularidad entre los dos siglos, lo sitúa en el cuarto lugar en frecuencia entre todas las diócesis.

- En la provincia limeña es crítico el caso de Cuzco, Guamanga y Truxillos que no superaron 3 y 4 preceptos ejecutados en todo el período.

\subsection{Observaciones específicas a la frecuencia de la visita ad limina}

- La frecuencia de la visita ad limina en estas provincias alcanza un tercio en relación con la norma sixtina, fijada cada diez años. Para la comprensión de esta dinámica, hay varios factores que aportan en la elaboración del diagnóstico. Entre los factores que alteraron el cumplimiento del precepto están: la distancia entre Roma y la diócesis fue el de mayor peso, en el ritmo decenal. La variación se verifica calculando el tiempo entre la partida del procurador y la ejecución de la norma propiamente, que es de dos años máximo; la instalación de los obispos en la diócesis es otro factor que altera la frecuencia, pues entre el nombramiento y toma de posesión, hay otros dos años lo que dificulta el ritmo decenal. Con estos dos elementos el ciclo no fue de diez, sino de 15 y más años. Luego, la práctica real sería cercana al $50 \%$, de lo que podría haber sido. Otra razón que explica situaciones particulares de algunas diócesis, fue la prolongada sede vacante. ${ }^{4}$

4 Dos casos extremos: la diócesis de Arequipa. entre el primer proceso de creación de la diócesis en 1577 y la segunda en 1609 y la ejecución de la erección en 1619 transcurren cerca de 40 años; Concepción de Chile, con la constante guerra y el clima adverso, hicieron que ella se constituyese en una diócesis de tránsito, suma más de cincuenta años de sede vacante.
- La brusca caída de la frecuencia de los prelados de Lima en el s. XVIII. Se detecta una doble fuente de causas en el caso limeño. Primero, la sucesión episcopal en el s. XVIII fue un asunto crítico. Desde 1708, deceso de Liñán y Cisneros, hasta 1714, hay seis años de sede vacante; y hasta 1761 un promedio de 5,6 años teóricos de sede con obispo, años que se deben ajustar al tiempo que corre entre el nombramiento y la toma de posesión, cerca de un año. La otra causa, se refiere a las reformas - políticas y religiosas - que introdujo la dinastía borbona desde 1753. Entre las reformas tocantes a la Iglesia está el proceso de secularización de las parroquias, la reducción de los bienes eclesiásticos y la expulsión de los jesuitas e incluso alcanzó la norma de la visita ad limina. La situación de Lima es muy nítida hacia fines del s. XVIII, hay dos arzobispos que gobiernan, uno 17 y el otro 23 años; ${ }^{5}$ coincide con la ejecución de las reformas borbónicas y la ausencia de visita ad limina de estos dos prelados. ${ }^{6}$

- La práctica de visita ad limina en las diócesis sufragáneas "periféricas" respecto a la metrópolis. La Tabla 1 muestra que el incumplimiento del precepto de las Iglesias sufragáneas, se agudizó en las zonas más cercanas a Lima, siendo agudo el fenómeno en Cusco, Guamanga, Truxillos. Mientras que en aquellas más lejanas del centro, como Quito, Arequipa y Santiago tienen alta frecuencia y en el s. XVIII fueron más regulares que el resto. Una primera explicación está en la geografía y el tipo de administración de la Iglesia: autoconciencia de los obispos de su autonomía en la administración eclesial y en las facultades propias que les daba el derecho; entonces, la lejanía con la metrópolis - política y eclesial- no impidió su regular funcionamiento, incluso creó espacio para la práctica de la autonomía real.

Las diócesis extremas-periféricas como Panamá por el norte y Concepción de Chile por el sur y Asunción en Paraguay por el sureste, presentaron otros factores. En estas tres diócesis la inestabilidad episcopal y política, se tradujo en sedes vacantes o en la inestabilidad del territorio, como fue la guerra de Arauco, en el sur de Chile. Estos factores hicieron que la geografía humana, la física o la política frenaran un desarrollo más consolidado hacia fines del s. XVIII.

\subsection{Otras observaciones sobre la frecuencia de la visita ad limina}

- Traslado del obispo y frecuencia: La historiografía ha sostenido que el traslado de obispos como política de la carrera eclesiástica. El ritmo de traslados entre las diócesis fue real, tanto dentro de un mismo

5 Cuando la Corona instruyó en el año 1771 que el proceso de visita ad limina fuese visado en Madrid, fueron arzobispos limeños Diego Antonio de Parada (1762-1779) y Juan Domingo González de la Reguera (1782-1805).

6 En estos años se convocaron y celebraron los Concilios Provinciales de 1772, los que no fueron aprobados por Roma. Cf. Hera 1992; Duque Alcaide 2011. Ambos autores ofrecen el proceso de convocación, celebración y la promulgación de estos concilios del s. XVIII, en contexto del regalismo. 
arzobispado como con otros. Al dar seguimiento al traslado, se observa: primero, se evidencia que ayudó a disminuir el tiempo de instalación del obispo -entre el nombramiento y la toma de posesión-, a un promedio de un año; segundo, los traslados no se perciben como un circuito de poder, sino como una política de gestión eficiente para la conducción eclesial. Hay casos singulares como los de Fernando Arias de Ugarte, Pedro de Villagómez, Liñán de Cisneros en la arquidiócesis de Lima.

- El rol de los procuradores: recurrir al procurador se fijó en la norma sixtina de 1585, a fin de resolver cuando el obispo estaba impedido de realizarla personalmente. Estos procuradores, generalmente, fueron los visitadores que designaban las congregaciones religiosas, para visitar sus provincias. Solo un prebendado de Lima, Juan Francisco de Valladolid, realizó la visita ad limina, aprovechando que había sido enviado a Roma para seguir el proceso de canonización del arzobispo Mogrovejo. Los sustitutos de los procuradores fueron religiosos de la misma orden religiosa y, en algunos casos, funcionarios de la Corona o prelados en la curia romana.

- Las normas patronales y la norma sobre el cumplimiento de la visita: el cumplimiento de la visita por parte del obispo implicaba una doble fidelidad: con Roma y con la Corona. ${ }^{7}$ La documentación no ofrece tensión de ningún obispo con estas instituciones. Desde la promulgación de la Bula de 1585 hasta le Cédula Real de 1771, esto es, en más de ciento cincuenta años, la Corona no promulgó ninguna norma que obligase al obispo a visar los documentos en el Consejo de Indias; prueba de ello, son las sustituciones de procuradores, las que se ejecutaron en Madrid. Solo con las reformas religiosas borbónicas, se normó que la documentación debía ser visada en Madrid, asunto que ocurrió recién en $1771 .^{8}$ Por el otro lado, el vínculo con Roma se observa cordial y fraterno. Los registros vaticanos de la visita dejaron constancia de las prórrogas para enviar la Relación sobre el estado de la Iglesia y que los procuradores fueron aceptados. ${ }^{9}$

\section{El deSARRollo de LA METROPOLITANA DE LiMA DESDE LAS RELACIONES DE VISITA AD LIMINA}

Este segundo apartado aborda la frecuencia de la visita ad limina realizada por los arzobispos de Lima. Para ello, se expondrán los antecedentes sobre la datación de esas y sobre la institución del procurador. Para la datación se anotan dos fechas: la primera indica la data fijada en Lima

7 La fórmula fue la misma con mínimas variaciones, pero el contenido es el mismo: el Dr. Dn. Luis Francisco Romero por la gracia de Dios y de la Santa Sede Apostólica, obispo de la ciudad de Santiago de Chile y su Reino, Provincia del Perú del Consejo de su Majestad del Rey Católico de España. Archivo Secreto Vaticano (ASV), Relaciones diocesanas Santiago de Chile, caja 411.

8 Sobre la medida Real de someter la documentación de la visita ad limina en 1771 al Consejo de Indias, no hay antecedentes en el A. S. Vaticano. La Real Cédula se adjuntaba entre los documentos que acompañaban el nombramiento de obispo.

9 Camus Ibacache 1994. en el documento más antiguo; y, la segunda, aquella que certifica que se cumplió con el precepto. Acerca del procurador, se registra el nombre del sacerdote o laico, se incluye el sustituto cuando corresponde. Estos asuntos dan luces sobre el procedimiento y el cumplimiento del precepto. Una vez abordado el procedimiento, se tratan los contenidos de las Relaciones, para desde ellas deducir la estructura del relato del texto y describir el desarrollo de la diócesis limeña.

La provincia eclesiástica de Lima fue creada en 1546, con las siguientes diócesis sufragáneas: Cusco, Castilla de Oro o Panamá, Quito, León o Nicaragua y Popayán; ${ }^{10}$ luego, entre 1561 y 1575 se agregan Sucre, Santiago y Concepción de Chile. A la fecha de la visita ad limina del arzobispo Mogrovejo, se incluyen Tucumán y Asunción de Paraguay. Se ha indicado que en 1609 se desmembraron de Lima varias diócesis, para dar origen al arzobispado de Sucre.

Los instrumentos jurídicos usados por los obispos, fueron: carta del obispo al pontífice; poder dado al procurador y la Relación sobre el estado de la iglesia. Los obispos adjuntaron otros documentos, como la profesión de fe y el juramento. Una innovación se observa en el respaldo jurídico que los obispos dieron al proceso de visita ad limina realizado por procurador. Para tal efecto, ellos invitan a declarar a testigos ante notarios públicos sean civiles o eclesiásticos. Los idiomas usados fueron el latín, italiano y castellano. También se conserva un documento elaborado en la curia romana, que es un resumen sobre el estado de la iglesia redactado por el secretario de la Congregación del Concilio; en ocasiones se agregan glosas al texto de la Relación, con las indicaciones canónicas para aconsejar, orientar, corregir o apoyar al obispo, o para invitarlo a realizar una reforma o acción que favorezca el desarrollo de la Iglesia.

\subsection{La práctica y frecuencia de la visita ad limina de la dió- cesis de Lima}

La Tabla 2 sobre la frecuencia de visita ad limina en la diócesis de Lima ofrece información sobre los procuradores y sus sustitutos. En la columna central se indica la datación en Lima y entre paréntesis la datación registrada en Roma.

10 Para la referencia en el ASV de las Relaciones Diocesanas de las diócesis de la Provincia de Lima y de Sucre, se indica la Diócesis y n.o de la Caja de ubicación en el Fondo de la Congregación del Concilio. Provincia de Lima: Lima n.o 450, Arequipa n.o 75, Cusco, n. 285, Quito n. 672, Guamanga n.o 379, Truxillo, n. 821, Santiago de Chile n. 411, Imperial o Concepción de Chile n.o 248, Panamá n. 616. Provincia de Sucre: se creó en 1609: Sucre (La Plata o Charcas) n.ㅇ 649, La Paz n.o 616, Santa Cruz de la Sierra n. 277, Tucumán n. 823, Paraguay n.은 619, Buenos Aires n. 135. Dos consideraciones importantes: a Lima aparecen vinculadas hasta inicios del s. XVII la diócesis de Popayán n.은 655, a pesar de haber sido integrada al arzobispado de Santa Fe desde su creación; aún más excepcional es Nicaragua n. 576 pues también aparece vinculada, pero que desde 1670 será sufragánea de México y, desde 1743, al arzobispado de Guatemala. La diócesis de Panamá en 1900 fue constituida sufragánea de Cartagena de Indias; Quito fue sufragánea de Lima hasta 1848; y Buenos Aires, erigida diócesis en 1620, permaneció como sufragánea de Sucre hasta 1865, cuando fue creado el arzobispado. 
TABLA 2

Frecuencia de la visita ad limina de los arzobispos de Lima

\begin{tabular}{|c|c|c|}
\hline Arzobispos & Dataciones & Procuradores \\
\hline $\begin{array}{l}\text { Seis arzobispos: todos con } \\
\text { ministerios extensos. }\end{array}$ & $\begin{array}{l}12 \text { visitas ad limina } \\
\text { realizadas en el s. XVII; y } 1 \\
\text { en el s. XVIII }\end{array}$ & $\begin{array}{l}\text { Los procuradores fueron religiosos que ejercían cargo similar en su Orden religiosa. Escasos fueron } \\
\text { clérigos seculares y menos aún civiles. Excepción el caso de Lima con F. Valladolid, quien fue enviado } \\
\text { para dar seguimiento a la canonización de T. de Mogrovejo. }\end{array}$ \\
\hline Toribio de Mogrovejo & $1599(01 / 1603)$ & Bartolomé Pérez S.J, sustituido por Diego Torres SJ. \\
\hline Bartolomé Lobo Guerrero & $1611(07 / 1612)$ & Fr. Juan Núñez OFM. \\
\hline B. Lobo Guerrero & $1614(11 / 1615)$ & Fr. Juan Vásquez OFM. \\
\hline Fernando Arias de Ugarte & $1631(01 / 1634)$ & Alonso Mexías S. J y Bartolomé Rotam. \\
\hline Fernando Arias de Ugarte & $1637(04 / 1637)$ & Fr. Bentura de Salinas OFM. \\
\hline Pedro de Villagómez & $1642(09 / 1645)$ & Fr. Miguel de Aguirre OEA. Bartolomé Tafur SJ. \\
\hline P. de Villagómez & $1651(09 / 1655)$ & Prebendado Juan Francisco de Valladolid. \\
\hline P. de Villagómez & $1660(07 / 1662)$ & Prebendado J. F. de Valladolid. \\
\hline P. de Villagómez & $1669(07 / 1671)$ & Fr. Antonio González OP e Iban de Urquiza SJ. \\
\hline Melchor de Liñán y Cisneros & $1678(07 / 1680)$ & Prebendado J. F. de Valladolid, Diego de Valladolid y Juan Meléndez. \\
\hline M. de Liñán y Cisneros & $1690(02 / 1692)$ & Ildefonso de los Ríos y Berris. J. F. de Valladolid (deceso). \\
\hline M. de Liñán y Cisneros & 1698 documento único & $\begin{array}{l}\text { Se conservan certificados de las basílicas. Luego, un documento en italiano, donde se dice: que se cumplió } \\
\text { con el recepto de la visita a las basílicas, y se explica que se han perdido documentos en el viaje y, se } \\
\text { solicita que sea admitido a don Ildefonso de los Ríos, en fecha «9 agosto 1698, Ildefonso de los Ríos». }\end{array}$ \\
\hline Antonio de Zuloaga & $1721(07 / 1722)$ & $\begin{array}{l}\text { Certificados de basílicas; poder a Andrés de Chavarri «Contador general del Consejo de la Suprema } \\
\text { Inquisición»; luego en el anverso, se anota: «en la villa de Madrid, el } 16 \text { abril de } 1722, \text { A. Chavarri da } \\
\text { poder al presbítero Antonio Aga, Bibliotecario del Ilmo. Acquaviva y al sr. José de Herrera de la Embajada } \\
\text { de España en Roma, para hacer v. ad limina...». }\end{array}$ \\
\hline
\end{tabular}

\subsection{Los contenidos en las Relaciones diocesanas de la metropolitana de Lima $^{11}$}

Por la relevancia de la vida y la obra pastoral de Mogrovejo se ofrece una síntesis sobre el cumplimiento del precepto ad limina ${ }^{12}$ Además, porque la visita ad limina de Mogrovejo fue la primera de Lima y entre las primeras del continente. Esta documentación ofrece antecedentes de la Iglesia limeña desde su creación como metropolitana en 1546; presenta vínculos con otras diócesis y se observa el perfil y rol del procurador.

Una aclaración preliminar que tiene relación con documentos que se conservan en el A. S. Vaticano, de la diócesis de Tucumán, el primero datado el 12 de diciembre de 1595, en la Ciudad de los Reyes, que corresponde al poder que el obispo Fernando de Trexo dio a Fr. Luis Jerónimo de Ore OFM, del cual se deduce que este cumplimiento del precepto sería más antiguo que aquel del arzobispo; el segundo documento es una brevísima Relación, que en su reverso registra: "anno dni. 1609» y firma: "frater luduvicus Hieronimus»; el tercero, resuelve mejor el problema, en el año 1608 el obispo Trexo cumplió con el precepto a través

11 Maldavsky 2002. La autora propone que el proceso de Mogrovejo y aquel del procurador fueron dos visita ad limina; este estudio aporta mayor precisión y sostiene que fue uno solo.

12 Antecedentes sobre Mogrovejo y de su obra pastoral son abundantes. El proceso de canonización iniciado en el s. XVII - beatificado en 1679- impulsó trabajos biográficos. Últimamente se han publicado documentos de la visita pastoral. El arzobispo era doctor en ambos Derechos, experto en el Concilio de Trento y conoce el catecismo de Paulo V. Llegó a Lima el 1581. Entre la publicación de la Bula Visita ad Limina de 1585, de Sixto V, y la Relación ad limina de 1599 existe un margen estrecho de tiempo, para conocer la práctica de otros obispos. Estos antecedentes formativos ayudan a comprender tanto la estructura de la Relación como otros documentos que son parte del dossier de 1599/1601. de otro procurador, Alonso Mexias, SJ, ${ }^{13}$ Con estos antecedentes se afirma que Fr. J. de Ore cumplió con el encargo de 1595 pero diferido a 1609, y se deduce que la documentación de Mogrovejo sigue siendo la más completa y antigua.

La Relación del arzobispo y reelaborada por el procurador, se constituyó en modelo para los sucesores, en especial por la estructura del relato de la Relación, cuya nota principal fue ser una radiografía de los aspectos fundamentales de la institución eclesial. ${ }^{14}$ Seguirla en el detalle mostrará con cierta profundidad el nivel de desarrollo de la diócesis, asunto que se evidenciará al estudiar las Relaciones de los sucesores de Mogrovejo. También se observará el tránsito desde un tipo de desafío pastoral hacia otro en el transcurso de dos décadas, desde la idolatría a los problemas conventuales femeninos.

Los documentos del proceso de visita ad limina Mogrovejo/procurador -1599-1603- comprende cinco documentos: dos poderes dados a Bartolomé Pérez SJ, en castellano y latín de mayo 1599; el tercero es una brevísima descripción del seminario; el cuarto una copia del Breve enviado por Gregorio XIII al arzobispo, con el cual el arzobispo probaba que le han sido dadas facultades, para celebrar sínodos y concilio provincial; y, el quinto, la Relación.

13 ASV. Relaciones diocesanas diócesis de Tucumán, del obispo Fernando de Trexo, caja 823. Respecto al fraile franciscano Luis Jerónimo de Oré, nació en Guamanga-Perú, en 1554. Notable escritor, historiador y pastor. Hacia 1587 se le ubica en la Corte de Madrid, para editar sus libros; en 1606 pasó a Italia. En marzo de 1620 el Rey le presentó para obispo de Concepción de Chile. Su deceso es en marzo de 1630. Cf. Araya. 1976: 28-31.

14 Es necesario indicar que en la normativa de Sixto V, en 1585, no se fijó un esquema para la elaboración de la Relación; Benedicto XIII recién en 1725 promulgara un Instructivo, que establece un esquema de doce capítulos, para redactar la Relación sobre el estado de la iglesia. 
A continuación algunos extractos, que muestran el razonamiento del arzobispo, respecto a la visita ad limina:

Lo mandado por Sixto V, sobre el precepto de Visita y Relación del estado de la Iglesia [...; luego, se excusa] en razón de la mucha distancia que ay entre estas partes para no poder irse como consta en las cartas que en su nombre me han enviado los Cardenales Montalco y Gerónimo Malbes, al 28 de agosto de 88 y 10 de junio de 91 . Asimismo a la que V. S. me dijo que Alexandro Putignanno Vissitase limina Apostolorum y que fuese admitido para esto y que dentro de cuatro años yo enviase Relación del estado de esta Iglesia, me escribió en de V S el Cardenal Malbes en 96, a lo cual he acudido con mucha diligencia y cuidado... y tengo aviso y testimonios de averse hecho la Visita en mi nombre los años $84,85,88,91,92$ y 95.

Luego, abunda en particularidades jurídicas: dice que le satisface hacerlo cada 10 años, como manda su Mutuo Proprio; luego, solicita un Breve para que «pueda hacer la Visita por poder por todo el tiempo que él viviese, por cualquier persona que tuviese mi poder»; y termina con la siguiente anotación:

La Santidad de Gregorio XIII me concedió un breve para que cumpliese celebrando Concilios Provinciales de siete en siete años y diocesanos de dos en dos por el tiempo que viviese. La Santidad de Gregorio XIV así mismo me escribió una carta, cuya copia autorizada va con esta, llena de regalo y favores.

En la introducción de la Relación, señala:

Relación y memorial... Después que vine a este arzobispado de los Reyes de España por el año de 81, he visitado por mi propia persona y estando impedido por mis visitadores, muchas y diversas veces el distrito conociendo y apacentando mis ovejas, corrigiendo y remediando lo que ha parecido como nuevo y predicando los domingos y fiestas a los indios y españoles cada uno en su lengua y confirmando mucho número de gentes, que han sido más de 60 mil animas y caminando más de seis mil leguas, muchas veces a pie por caminos muy fragosos... por partes remotas de indios cristianos que de ordinario traen guerra con los infieles a donde ningún prelado ni visitador había estado.

Anota que ha «Ejercitado de pontifical ordenando muchas y diversas veces a las personas que ha parecido conveniente y consagrado obispo y gran cantidad de curas dejando proveídas de ellas las iglesias». Resume que ha "celebrado dos Concilios Provinciales uno el 83 y el otro de 91 y ahora tengo convocado para otro...»; y que se ha celebrado Sínodo diocesano en 1572, 74, 75, y 76 y los años 1583, 1590, 1592, 1594, y 1596.

Luego, describe el estado de la Iglesia, señala:

- Hay 3 parroquias en Lima, 4 hospitales, 4 ciudades y 5 villas con muchos monasterios; 122 doctrinas de indios, de frailes "poco más o menos»; clérigos 118 más o menos.

- Tres colegios y seminario y muchas cofradías.

- Las dignidades de la iglesia catedral son: deán, arcediano, chantre, maestre escuela y tesorero; además 10 canónicos y 3 racioneros, 4 curas y otros ministros cantores con música e instrumentos. Los diezmos se distribuyeron según las leyes de la Iglesia y las reales.
En el proceso de Mogrovejo/procurador se conservan otros documentos, que están fechados desde agosto del año 1601 hasta el 20 de mayo de 1603. Estos documentos pueden inducir a presentarlos como procesos distintos. Los antecedentes para abordar el aparente problema y proponer la solución se plantea lo siguiente: primero, indicar que el procurador Bartolomé Pérez SJ fue sustituido por Diego de Torres, SJ; segundo, señalar que la Relación firmada por el padre Torres se titula: "la Visita es del Arzobispo y de otros obispos del Reino peruviano». Y tercero, entre los folios se conservan los poderes dados por otros obispos, esto es: Sucre y Cusco a inicios del año 1601 y Cartago y Popayán en agosto de 1601.

No hay dudas, que las dos Relaciones forman parte del mismo proceso iniciado en 1599. Es evidente que el procurador Diego de Torres, visitador de la provincia jesuita, al ir pasando por las diócesis fue recogiendo documentos de los otros obispos, para que cumplieran con el precepto, asunto que se prueba con los poderes dados en el obispado de Sucre y del Cusco a inicios de 1601 y los de Cartago y Popayán en agosto del mismo año. Por otro lado, se deduce que el jesuita conoció del Concilio limeño de 1601, pues tal hecho está incorporado en la Relación que él reelaboró. La Relación reelaborada cubre información de varios años más -1601-1603- y de otros obispos, sin excluir aquella que registra el arzobispo Mogrovejo. No se conservan los poderes de los obispos de Quito y Panamá, de cuyas diócesis el jesuita Torres hace referencia.

En el reverso se anota la datación del funcionario de la curia romana: «el día 24 enero 1603 fue admitida a la Visita por Procurador». En síntesis:

- «Relaciones del Arzobispado de Lima y otros seis obispos del Reino del Perú en las Indias Occidentales, realizado por Diego de Torres S. J., procurador».

- El seminario «donde están y entra mucha gente pobre en conformidad de lo proveído por el Sto. Concilio de Trento». Además, informa que va a construir una iglesia, para que se rece misa diaria y el patrón es santo Toribio de Astorga.

- Sobre el concilio provincial, precisa: 1583, 1591 y un tercero 1601. En el de 1583 se ordenó hacer catecismo y confesionario.

- Los sufragáneos son diez: Cusco, Charcas, Paraguay, Tucumán, Quito, Panamá, Nicaragua, Popayán, Santiago y la Imperial de Chile. ${ }^{15}$

- La iglesia catedral tiene: tribunal eclesiástico, cinco dignidades (deán, canónico, racionero, sacristán y ecónomo); cuatro acólitos, coro y organista, ocho personas.

- Hay tres monasterios de monjas: de la Encarnación, agustino, con 130 monjas; de la Concepción de la Santa Clara, con clausura; bajo el título Santísima Trinidad, de la Orden Cisterciense, ${ }^{16}$ con 40 monjas, casa cómoda, templo pequeño.

15 En el año 1546 se creó el arzobispado de Lima con las sufragáneas indicadas en el apartado anterior, con la respectiva evolución de las jurisdicciones. En la Relación de Mogrovejo aún aparecen los obispados de Panamá, Nicaragua y Popayán vinculados a Lima. En esta perspectiva Lima fue una metrópolis articuladora del área del Pacífico.

16 Stieger y Roberts 1987. Da cuenta de esta comunidad femenina, y sostiene que no es una comunidad de la Orden, sino nacida de 
- Cinco comunidades de varones: Santo Domingo, San Francisco, San Agustín, de Nra. Sra. de la Merced y jesuitas. Tanto los jesuitas como los franciscanos descalzos tienen otra casa fuera de la urbe.

- Por otra parte, señala que hay 4 parroquias, tres colegios (una academia, el seminario, colegio jesuita), entre ellos cuentan con 30 profesores.

- La ciudad de Truxillo tiene 4 parroquias, 3 comunidades de varones y 1 de mujeres; en Chachapoya, 2 parroquias, dos cenobios; Ica, dos parroquias y tres cenobios; en Chacanza, 1 parroquia y 1 monasterio; en Zana, 4 párrocos en dos parroquias, 4 monasterios; Callao 4 parroquias y monasterios.

- Hay alrededor de 122 sacerdotes seculares en total.

- En la Academia Real se imparte: Derecho, Teología, Filosofía y Escuela de Lenguas.

En el mismo cuerpo documental se ofrecen aspectos de las sufragáneas: ${ }^{17}$

- Cuzco con dignidades y canónicos. Monasterio de varones que son de los mismos de Lima; 7 parroquias de indios, seminario, confraternidades: Por su parte, en Arequipa (además de dar cuenta de una erupción volcánica, que ha alcanzado los valles) indica 3 monasterios de varones, 2 de mujeres y 1 dominico que atiende parroquia. En Guamanga 3 monasterios varones, 1 de mujeres y se ha realizado la visita pastoral.

- Charcas o Platense. Tiene dignidades y canónicos, templo magnífico, 5 monasterios, 1 femenino bajo el ordinario, colegio y seminario. Parroquias de indios 3. En Potosí varias parroquias de indios, total 15 parroquias administradas por regulares.

- Quito. Tiene 6 parroquias de indios, colegio y seminario con la Compañía; 5 monasterios, 3 de mujeres y 2 de varones.

- Popayán. La única información refiere que el obispo fue consagrado por el de Lima.

- Panamá. Breve información: no hay indios en la ciudad, 4 monasterios, 1 de mujeres.

- Cartago. Se atiene a indicar el problema de los piratas y el templo que es fastuoso. Monasterios 4, «hay poquísimos indios en la ciudad, muchos etíopes».

Los otros documentos son:

- Poder del obispo de Cartago, Juan de Adrada a Diego de Torres para que realice visita ad limina, 20 de agosto de 1601.

- Documento de Francisco de Alarcón, notario, certifica que los obispos de Popayán, don Juan de la Roca, y de Lima, don Toribio de Mogrovejo, dan poder.

\subsection{Las Relaciones de los arzobispos de Lima, desde 1603}

La Tabla 3 aborda la secuencia y datación de la visita y la Tabla 4 aspectos cuantitativos sobre el clero, seminario, monasterios femeninos, que los arzobispos reportan en las Relaciones. Estos datos permiten formarse una visión global de la diócesis, método que más adelante permitirá acercamientos comparados con las diócesis periféricas.

TABLA 3

Contenidos genéricos en las Relaciones de los arzobispos de Lima

\begin{tabular}{|c|c|c|}
\hline Arzobispo & Visitas & Contenidos relevantes \\
\hline Arz. Toribio de Mogrovejo. 1599/1603 & 1 & $\begin{array}{l}\text { La Relación fue elaborada en } 1599 \text { y presentada en Roma, en enero del año de 1603, junto a otras breves } \\
\text { Relaciones de las diócesis sufragáneas del arzobispado, por el procurador Diego de Torres, SJ. La diócesis de } \\
\text { Lima muestra: } 4 \text { parroquias, y con otras villas se alcanzan a } 12 \text { parroquias en total. Se excluyen los datos de } \\
\text { Truxillos, Chancanza y Chachapoyas. }\end{array}$ \\
\hline $\begin{array}{l}\text { Arz. Bartolomé Lobo Guerrero. } \\
1611 \text { y } 1614\end{array}$ & 2 & $\begin{array}{l}\text { Fueron dos preceptos ejecutados. La Relación de } 1614 \text { ofrece un panorama completo sobre el desarrollo de } \\
\text { la diócesis: entre los aspectos a subrayar la distribución social de los hospitales, para españoles, indígenas, } \\
\text { marineros, clero, mujeres, enfermedades incurables. }\end{array}$ \\
\hline $\begin{array}{l}\text { Arz. Fernando Arias de Ugarte. } \\
1631 \text { y } 1637\end{array}$ & 2 & $\begin{array}{l}\text { De las dos Relaciones, aquella del año } 1637 \text { aporta el crecimiento y desarrollo de los monasterios femeninos, } \\
\text { con información demográfica de ellos. En total 6: Encarnación, Concepción, Clarisas, Trinidad, San José, Sta. } \\
\text { Catalina de Siena. }\end{array}$ \\
\hline $\begin{array}{l}\text { Arz. Pedro de Villagómez. } \\
1642,1642,1660 \text { y } 1669\end{array}$ & 4 & $\begin{array}{l}\text { En la Relación de } 1660 \text { ofrece el incremento de los monasterios de monjas, en dos: descalzas S. Agustín de } \\
\text { Santa María del Prado (1638) y Sta. María del Monte Carmelo. }\end{array}$ \\
\hline $\begin{array}{l}\text { Arz. Melchor de Liñán y Cisneros. 1678, } \\
1690 \text { y } 1698\end{array}$ & 3 & $\begin{array}{l}\text { La Relación de } 1690 \text { es muy completa, ella ofrece una visión completa de la obra pastoral de la diócesis, con } \\
\text { información histórica sobre fundaciones de órdenes religiosas y fundaciones pías. Se mantiene los monasterios } \\
\text { femeninos. }\end{array}$ \\
\hline Arz. Antonio de Zuloaga. 1721 & 1 & $\begin{array}{l}\text { Solo se conservan documentos: poder a Andrés de Chavarri, contador general del Consejo de la Suprema } \\
\text { General Inquisición; la carta al pontífice, fechada en Lima, día y mes (ilegible) de 1721. Y los certificados de las } \\
\text { basílicas, junio } 1722 \text {. }\end{array}$ \\
\hline Total: Seis prelados & 13 & \\
\hline
\end{tabular}

la voluntad de la Señora Lucrecia de Sansoles Viuda de Vargas y de su hija Mencía de Vargas. La comunidad fue reconocida por Gregorio XIII, en 1584.

17 Efectivamente, en las Cajas de estas diócesis en el A.S. Vaticano se encuentra la referencia de los obispos que dieron el Poder a Diego de Torres; y en Sucre, Cusco y en Panamá se agregó el obispo Pablo de Artiaga. En la Caja correspondiente a Popayán no se conserva este documento.
La Tabla 4 tipifica cuantitativamente el desarrollo de la estructura eclesial, en cuanto: cabildo, número de parroquias, curatos, seminario y colegios, clero, hospitales, excluyendo las religiosas, se las tratará de forma separada por la relevancia que ellas tuvieron y una sección para otros aspectos importantes. Estos datos junto con los anteriores van conformando una visión de la consolidación de la 
TABLA 4

Aspectos cuantitativos que registran las Relaciones sobre la iglesia limeña

\begin{tabular}{|c|c|c|c|c|c|c|}
\hline Estadísticas & 1603 & 1611 & 1637 & 1651 & 1669 & 1690 \\
\hline Cabildo & 5 dignidades & Completo & Completo & Completo & Igual & Igual \\
\hline Parroquias & $\begin{array}{l}12 \text { parroquias: } 4 \text { Lima, } \\
6 \text { más en las otras } \\
\text { villas }\end{array}$ & $\begin{array}{l}12 \text { parroquias: } 4 \text { Lima } \\
\text { y en } 6 \text { villas, con } \\
\text { parroquias }\end{array}$ & $\begin{array}{l}\text { 19: } 4 \text { en Lima y } 15 \text { en } \\
\text { las otras villas }\end{array}$ & $\begin{array}{l}4 \text { en Lima y en las } \\
\text { villas. }\end{array}$ & $\begin{array}{l}\text { 20: } 4 \text { en Lima y } 16 \text { en } \\
\text { otras villas }\end{array}$ & \\
\hline Curatos & 100 & 130 & 147 & & 157 y anexos & \\
\hline Seminario/Colegios & $\begin{array}{l}\text { Seminario y dos } \\
\text { colegios }\end{array}$ & & Seminario, 3 colegios & $\begin{array}{l}\text { Seminario, } 6 \text { colegios, } \\
\text { Universidad Real }\end{array}$ & & \\
\hline Clero Secular & 122 & --- & --- & --- & 100 & 200 total \\
\hline Clero Regular & 5 Casas & 12 casas & 11 casas & & $\begin{array}{l}\text { Clero de Fco. de Paula; } \\
\text { y Felipe Neri }\end{array}$ & \\
\hline Hospitales & 3 & 7 & 7 & -- & De San Juan de Dios & 12 \\
\hline Conventos Femeninos & $\begin{array}{l}4 \text { en Lima, más } 10 \text { en } \\
\text { las villas }\end{array}$ & 6 & 8 & & & 13 \\
\hline Otros aspectos relevantes & $\begin{array}{l}\text { Ermitas dedicadas } \\
\text { a la Virgen de: } \\
\text { Copacabana, del } \\
\text { Socorro, Las Cabezas }\end{array}$ & $\begin{array}{l}\text { Idolatría prioridad } \\
\text { pastoral; divide la } \\
\text { población: españoles, } \\
\text { etíopes e indios }\end{array}$ & $\begin{array}{l}\text { Los conventos } \\
\text { femeninos surgen } \\
\text { como desafío } \\
\text { pastoral: reformar }\end{array}$ & & $\begin{array}{l}\text { Registra las ermitas } \\
\text { del } 1603\end{array}$ & \\
\hline
\end{tabular}

comunidad eclesial. Estos datos serán una referencia concreta y obligada, para comparar con el desarrollo de las diócesis periféricas.

\subsection{El estado de la Iglesia limeña desde las Relaciones de visita ad limina}

Las Relaciones de los arzobispos Mogrovejo, Lobo Guerrero, Arias de Ugarte, Pedro de Villagómez (cuatro visita ad limina y gobernó por 27 años: 1639-1678) y Liñán de Cisneros (tres visita ad limina), contabilizan una frecuencia censal en referencia a la norma, pero esta tendencia en el s. XVIII se redujo, solo se registra la del arzobispo Zuloaga, del año 1721.

Con estas Relaciones se observa el desarrollo y consolidación de la comunidad diocesana, con énfasis en la ciudad Lima. La documentación descrita expone asuntos sobre procedimientos para cumplir con el precepto, sobre la estructura de la Iglesia - evitando repetir los datos transcritos en las tablas-y, muy importante, acerca de la recepción de las reformas del Concilio de Trento. En síntesis:

\section{Sobre Procedimientos}

- Sobre el conocimiento del precepto de visita ad limina: tanto en el poder al procurador como en la carta al pontífice, los obispos señalan de la obligación de cumplir con esta norma. En el año 1642 el arzobispo Villagómez escribe: que «está obligado cumplir cada diez años con este precepto; para dar cuenta al Sto. Padre (Urbano VIII) y a sus sucesores de todo lo tocante a su oficio pastoral... y de todas las cosas en cualquier modo pertenecientes del estado de esta su iglesia, del gobierno del clero, del pueblo, y de la salud de las almas que le están encargadas». ${ }^{18} \mathrm{Y}$ que puede dar poder a procurador.

18 La expresión salud de las almas no es secundaria, es el corazón de la misión de la iglesia que define el C. de Trento: la salus animarum. Desde esta definición se explican la exigencia de la residencia del obispo,
- De la profesión de fe y juramento de fidelidad: solo el arzobispo Arias de Ugarte, en 1634, incluyó la profesión de fe y el juramento de fidelidad. ${ }^{19}$ La primera trata sobre el Credo, fidelidad al consenso de los Padres, la interpretación de las Escrituras, celebrar los sacramentos, creer en la transubstanciación, cumplir con el precepto de visita pastoral y, la segunda, es la obediencia a la sucesión apostólica. Otros arzobispos hacen referencia a estos actos jurídicos en la carta que envían al pontífice.

- El Cuestionario, las declaraciones y la comparecencia de testigos: el objetivo de este procedimiento fue probar las razones de por qué el obispo está impedido de viajar a Roma. El notario del arzobispo Arias de Ugarte registra varios testigos, quienes declaran que el obispo está impedido de cumplir personalmente con el precepto. Este es un procedimiento nuevo, del cual no se encuentra registro en otras provincias eclesiásticas. Los obispos incorporaron este Instrumento, a fin de tener seguridad jurídica del por qué no puede concurrir a Roma. ${ }^{20}$

En la documentación del arzobispo Villagómez del año 1642 , se conserva el legajo más completo, con las preguntas que debe responder cada testigo. En la lista de las preguntas y respuestas se descubre información de la diócesis, de personas o del ministerio del obispo. A continuación se transcriben algunos textos, que dan cuenta de lo comentado:

la visita canónica que debe realizar a la diócesis. La referencia a la residencia se encuentra siempre en los documentos, de forma especial en la carta del obispo al pontífice, en los testimonios de los testigos y en la Relación misma.

19 La profesión de fe y el juramento de fidelidad son dos actos jurídicos distintos que se realizan al momento de la consagración: la profesión de fe se refiere a dar lectura a la doctrina declarada en Trento sobre materias dogmáticas y el juramento de fidelidad es propiamente eso, es decir jurar obediencia a la sucesión de Pedro.

20 La fórmula de inscripción de los testigos que firman, es muy concisa: «el Padre Sánchez, capellán de la Catedral; Diego López, colector del arzobispado y Diego Mexias de Cabrera». 
- «Don Martín de Velasco y Molina, deán de la Catedral de Arequipa, provisor y Vicario General del Arzobispado hace comparecer ante mí a el licenciado Juan Bautista Ramírez, cura rector de la iglesia catedral; hace comparecer al doctor Alonso Osorio; Lucas de Palomares; Francisco Félix de Guzmán; Juan Santoro de Palma de la parroquia de San Marcelo, y a don Alonso Corbacho de la parroquia de Santa Ana, maestro de lengua quechua en la Real Universidad».

- La dimensión pastoral aparece desde la pregunta 3: "que si lo hace personalmente faltaría al oficio u obligaciones de su oficio por ausencia y que se requieren al menos cinco años para ir y volver con la decencia conveniente a su dignidad»; "que los canónicos son de edad y padecen enfermedad y que se excusaron para ir a Roma»; "si saben que los clérigos del arzobispado son curas ocupados en la administración de los santos sacramentos, que no pueden faltar a la residencia»; "que si saben que fray Miguel de Aguirre y B. ${ }^{\text {me }}$ Tafur están prontos a ir a Roma». La recepción jurada de los testigos la ejecuta el notario público, Melchor de Oviedo.

- Del nombramiento de procurador: se ha indicado que este encargo fue dado a religiosos, que eran procuradores de sus congregaciones. El arzobispo Villagómez al cumplir con la norma en 1651, registra el envío a Roma de un clérigo limeño. En la minuta - en italiano- se explica que el obispo por razones de gravedad de sus años, enfermedades y la lejanía le impiden viajar; luego, presenta al procurador: «Juan Francisco de Valladolid Canónico de la Santa Metropolitana Iglesia de Lima, del Reino del Perú, en las Indias Occidentales, presente en curia a la solicitud y beatificación del siervo de Dios Toribio Alfonso Mogrovejo». ${ }^{21}$ Suplica, «a V. Sta. Admitirlo a la Visita limina Apostolorum por Pedro de Villagómez, actual arzobispo».

- Certificado de las Basílicas de San Pedro y San Pablo: este documento se expedía en las Basílicas, y son más tardíos en aparecer. Los extiende el superior eclesiástico de las Basílicas. La datación de los dos certificados se diferencia entre dos días a una semana. En ellos se anota el nombre del obispo y el procurador.

\section{Sobre las estructuras eclesiales}

Las estructuras eclesiales son importantes pues ellas reflejan las reformas de Trento. Por ello, la estructura del relato de la Relación se elabora a partir de ellas. Estas son: descripción de la diócesis, obispo, capítulo, clero, seminario, monasterios, cofradía y termina con la descripción del pueblo de Dios. Todos los obispos tuvieron un grado de conocimiento sobre el precepto de visita ad limina.

\section{- Las diócesis Sufragáneas}

La diócesis de Sucre fue erigida en 1552 y elevada a metrópolis en 1609, teniendo como sufragáneas: Paraguay, erigida en 1546; Tucumán, erigida en 1570; Santa Cruz de la Sierra, erigida en 1605, y «Chuquiabo» o La Paz, erigida en 1608.

${ }^{21}$ La beatificación de Toribio de Mogrovejo se celebró en 1679 y la canonización en 1726, información esencial y sólida en Leonardi 1998.
En la Relación del año 1637 el arzobispado de Lima se visualiza estable en comparación con las sufragáneas, esto es, con nueve diócesis: ${ }^{22}$ Cusco, Quito, Arequipa, Guamanga, Trujillo, Panamá, Nicaragua, Santiago y Concepción de Chile. La última desmembración será Nicaragua, cuando pasa a formar parte de la provincia de Guatemala, en 1743.

\section{- Capítulo}

Esta institución fue un órgano importante en el gobierno de la diócesis, era como el senado del obispo. ${ }^{23}$ Para el obispo describir que las dignidades estaban proveídas, indicaba que se tenía un clero competente e idóneo. El número de prebendados siempre es aquel fijado en la bula de creación de la diócesis.

\section{- Parroquias y Curatos}

Las Relaciones ofrecen datos sobre el desarrollo de estos dos institutos y su distribución. Un asunto vinculado en esta materia fue la distribución del clero secular o regular en las parroquias y curatos, no son del todo nítido los datos que ellos registran. Cuando ellos informan sobre esta materia tienen clara las normas de Trento sobre concurso de provisión de parroquias y la orientación al clero secular que se deben tener. En la Relación del arzobispo Liñán y Cisneros, del año 1669, registra: 20 parroquias para españoles, 157 para indios y con anexos en las doctrinas.

\section{- Clero regular y secular}

Respecto a los presbíteros se informa de manera general: sobre su número, formación, responsabilidades. El arzobispo Liñán y Cisneros, en la Relación de 1690 es el más explícito, entre algunas afirmaciones: «los clérigos tienen buena formación, buena espiritualidad, de buenas virtudes para toda la feligresía». Además, subraya que son asiduos a cumplir con el Breviario, dan ejercicios espirituales a la comunidad, en tiempo de Cuaresma.

De los regulares se ofrecen otras descripciones: administran los colegios de sus órdenes o que tienen ministerios en los curatos, con la fórmula «hay muchos regulares en los curatos o en parroquias». Se evitan las estadísticas. Empero, en la tabla de temas cuantitativos se ha tratado de articular algunos datos, muy genéricos.

\section{- Monasterios femeninos}

Desde la Relación del arzobispo Mogrovejo se conserva información sobre el desarrollo del monacato femenino. Los prelados ofrecen estadística, juicios evaluativos, detectan problemas en la gestión y solicitan facultades para reformarlos. Algunas inferencias desde estas fuentes, que permiten describir esta institución eclesial, a saber:

22 Con la creación del arzobispado de Sucre se desmembraron de Lima: Sucre, La Paz, Santa Cruz, Tucumán y Asunción (Paraguay). Esta nueva jurisdicción se extiende, geográficamente, por la meseta oriental andina - desde La Paz (Bolivia) hasta Asunción (Paraguay)-, pasando por Tucumán (Argentina). La geografía impone un camino natural. Datos e información sobre las bulas de creación de jurisdicciones eclesiásticas, cf. Hernáez 1872: 728-731.

23 El Capítulo es una institución que reúne el cuerpo de canónigos de una iglesia catedral. La constitución de este órgano corresponde al pontífice. Las funciones de este órgano, antes del Concilio Vaticano II, abarcaban tanto asuntos litúrgicos como de apoyo a la administración de la diócesis. Cf. Donoso Vivanco 1855. Voz Capítulo, en tomo I: 292-293. 
TABLA 5

Aspectos cuantitativos que registran las Relaciones de los monasterios femeninos limeños

\begin{tabular}{|c|c|c|}
\hline Monasterio & Población de religiosa & Población de servicios \\
\hline Encarnación del Señor, Regla San Agustín. & Profesas de Coro 200; novicias 15; velo blanco 24 & $\begin{array}{l}\text { Oblatas 30; educandas y otras damas seculares 100; } \\
\text { ancillas, servicios } 250\end{array}$ \\
\hline $\begin{array}{l}\text { Título: Santísima Trinidad, de la Regla de San Benito, } \\
\text { llamadas de San Bernardo. }\end{array}$ & De coro 90; novicias 10; hermanas 20 & $\begin{array}{l}\text { Oblatas 20; educandas y otras damas seculares 50: } \\
\text { domésticas } 250\end{array}$ \\
\hline Purísima Concepción. Regla de San Francisco. & Profesas de coro 250; novicias 12; hermanas 30 & Ancillas y sirvientas 250 \\
\hline $\begin{array}{l}\text { Sta. M. }{ }^{\text {a }} \text { de la Peña, clarisas. Hábito S. Francisco. Fundada } \\
\text { por Mogrovejo. }\end{array}$ & Profesas de coro 184; novicias 10; hermanas 20 & $\begin{array}{l}\text { Oblatas 50: educandas y seculares } 80 \text { : sirvientas y } \\
\text { ancillas } 280\end{array}$ \\
\hline $\begin{array}{l}\text { Purísima Concepción del Patriarca Sn. José. Fundadas } \\
\text { por Lobo Guerrero. }\end{array}$ & $\begin{array}{l}\text { Las profesas antiguas fundadoras } 33 \text {, hoy son } 53 \text {; } \\
\text { novicias 4; hermanas } 20\end{array}$ & Oblatas 30. Todas participan a las Horas del Breviario \\
\hline Santa Catalina de Siena. Regla Santo Domingo. & Profesas de coro 140; novicias 6; hermanas 20 & Oblatas y adolescente educandas 30; ancillas 100 \\
\hline $\begin{array}{l}\text { Recoletas de San Agustín, Sta. María del Prado. Aprobada } \\
\text { por S. Sede, fundadas en sede vacante en } 1638 .\end{array}$ & Profesas de coro 33: hermanas 10 & Ancillas 20 \\
\hline S. Teresa de Jesús, fundadas por Arz. P. de Villagómez. & Coro 23; hermanas 20 & Sirvientes 3 \\
\hline
\end{tabular}

- El desarrollo fue sostenido en el siglo: tres monasterios en 1599, seis en el año 1637, ocho en 1651 y culmina con diez en 1690.

- El arzobispo Arias de Ugarte fue el primero en solicitar facultades para mejor conducción de los monasterios, afirma: «pues sin licencias es difícil reformar».

- El arzobispo Villagómez en 1651 registra los monasterios indicando la Regla que los inspira: Regla de San Agustín, de la Encarnación del Señor; Regla de San Bernardo, Santísima Trinidad; Sta. Ma de La Peña, Clarisas, la fundó el arzobispo Mogrovejo; Regla descalza Inmaculada Concepción, del patriarca San José; Regla Santa Clara, de S. Clara; Regla y título de S. Catalina de Siena; Regla descalza S. Agustín, S. María del Prado; Regla descalza y título S. María del monte Carmelo. ${ }^{24}$

- Los prelados ofrecen juicios cualitativos: en la Relación de 1651 se señala que progresan en la disciplina e incrementan sus vocaciones; a su vez, se registra la abundancia de monjas, demasiadas domésticas y fámulas. Ellas viven en medio de fragilidades, el clima es adverso, hay enfermedades. En este contexto, se afirma que la espiritualidad es difícil; que hay problemas con el ingreso de personas externas y se aprovechan en las ceremonias solemnes para ingresarlas. El prelado informa que "él las ha inducido a disminuir el número".

A continuación, la Tabla 5 recoge las principales casas en formato estadístico. La Relación de $1690^{25}$ es muy completa y presenta una descripción sobre el desarrollo de los monasterios. En otros términos, es una síntesis del desarrollo de los monasterios femeninos en cien años. La información que registra el documento toca asuntos sobre el origen

24 La Relación de 1651 ofrece estadísticas sobre el número de profesas, novicias, domésticas, jóvenes en calidad de educandas. En la Relación se registra un total 1270 religiosas, 1023 domésticas y educandas 139. Es interesante destacar que la Congregación de las Clarisas fundada por Mogrovejo tiene 292 religiosas, y el de Catalina de Siena 88 religiosas.

25 La estadística que se ofreció en 1651 ha variado en 40 años, en el grupo de las domésticas y educandas. En el periodo de Liñán y Cisneros, la Relación de 1690 anota: 1228 religiosas, domésticas 1130 y educandas 260. El incremento es notorio en los dos grupos, los cuales no son precisamente religiosas. fundacional, estadística, detalle social, étnico, educacional. Importante es la información que registra de los tres primeros monasterios, que se remontan a los arzobispos Loayza y Mogrovejo.

La Relación de 1690 ofrece información de las fundaciones, de los benefactores y las áreas pastorales que cubrían. El obispo relata que "a instancias de don Juan de Almoguera, logró de la Matrona Ana de Roblescón viuda de Diego de Tedia, la donación de cien mil ducados, para el Monasterio el Salvador». El monasterio de descalzas de la Merced o de la Misericordia, que remonta su origen a un antiguo beaterio de la Merced. Otros monasterios creados en su periodo, son: las Hermanas tercera orden penitencial de Sto. Domingo, Hermanas San Rafael de Viterbo de San Francisco y Hermanas de Jesús de Nazaret. Concluye afirmando:

"Los Monasterios viven con decoro y honestidad. Aquel del Carmelo es muy pulcro. Ante algunas adversidades, el Arzobispo Súplica-Solicitud, para que se le dé un tiempo especial de Jubileo universal, en las ciudades, villas y pueblos para dispensar irregularidades, censuras y dar indulgencias, para el bien de todo el pueblo».

\section{- Cofradías}

Este es un contenido ausente en las Relaciones; empero, en algunos de ellos se encuentran breves registros: el arzobispo Mogrovejo indica «hay tres colegios, seminario y muchas cofradías»; en 1611 el sucesor señala: "Hay confraternidades de laicos dirigidas desde la catedral: se dedican a ayudar a los huérfanos y pobres. Otra fundada por los dominicos con el mismo fin». Se subraya la ausencia de este contenido pastoral en las Relaciones, porque después de Trento dos cofradías adquirieron importancia, en el clima de reforma eclesial: la del Santísimo Sacramento y la de la Doctrina Cristiana, las que debían erigirse en todas las iglesias parroquiales. ${ }^{26}$ El obispo Carrasco de Santiago de Chile,

${ }^{26}$ Clemente VIII en la Constitución Quaecumque, del 7 de diciembre de 1604 , establece que «en una misma ciudad o pueblo no puede haber dos cofradías del mismo instituto...; esta prohibición no comprende a las cofradías del Smo, y de la Doctrina Cristiana, que pueden erigirse en todas las iglesias parroquiales». Cf. Lucii Ferraris. 1845. Voz Confraternitas, en Prompta Biblotheca, t. II, art. I, n. 45. 
en el Sínodo que celebró en 1688 , dedica un capítulo a la administración y gestión de las cofradías. ${ }^{27}$

\section{Sobre las reformas del Concilio de Trento}

\section{- Residencia episcopal}

El Concilio de Trento normó que el obispo y los clérigos seculares deben permanecer en sus jurisdicciones. Esta norma fue incorporada en las Leyes de Indias, por tanto, era muy difícil que un obispo saliera o abandonara su sede, por el contrario, ellos se esfuerzan en cumplirla. ${ }^{28}$ El arzobispo Arias de Ugarte en 1631, en el poder que da al procurador, registra: «que está impedido por Cedulas reales salir de las Indias». La Corona cuidaba que los obispos cumplieran con la residencia, mandada por Trento. Es en este horizonte eclesiológico que debe comprenderse porque estos obispos no viajaron a Roma, para cumplir con el precepto personalmente y se explica el protocolo de los testigos.

\section{- Visita pastoral}

El arzobispo Mogrovejo recorrió más de una vez la diócesis. El arzobispo Lobo Guerrero en la introducción de la Relación registra que llegó a su sede en el año 1609, que la Iglesia tiene sacerdotes doctos y cristianos y ha visitado todo el arzobispado: "Visité la iglesia catedral y todas las iglesias de la ciudad, Colegios, Seminario, hospitales, confraternidades, monasterios de monjas que con gran diligencia los sínodos anteriores han reformado. Hay tribunal del santo oficio, con ministros muy diligentes».

En 1637 Arias de Ugarte anota: durante 6 años realizó la visita pastoral, 23 años que no se hacía. Describe: «dos mil leguas he deambulado con grandes trabajos, y administrado los sacramentos».

El arzobispo Villagómez en la Relación de 1642, señala: de su ministerio en Arequipa, desde donde fue trasladado a Lima, en el mes de mayo de 1637, que realizó la visita pastoral, la que fue suspendida por enfermedad; la reinició y terminó en febrero de 1638. Caminó más de 300 leguas. En toda la visita confirmó más 20 mil almas. El prelado comenta que elaboró unos apuntes, que incluyen sobre la erección y los derechos de iglesia catedral, que celebró el Primer Sínodo de la Iglesia, con gran aprobación, que se cerró en diciembre de 1638. También celebró órdenes por casi toda la provincia, y pasó «a la De La Plata, sin Prelado».

Luego, continúa anotando que en 1639 no pudo seguir con la visita, pidió a dos padres de la Compañía «visitar en lo tocante a Idolatrías» en las provincias de Condesuyos y Collaguas, "las visitaron casi todas" y "otros dos visitaron la Provincia de Tarapacá»; y que envió a «Fr. Bernardo de Cárdenas electo obispo del Paraguay, a que visitase lo referente de la dicha provincia...».

Finaliza con la siguiente información: deja constancia que no había obispo en La Paz ni en Guamanga y reitera

27 Obispo Bernardo Carrasco. Sínodo diocesano celebrado por el IIImo. Dr. Fr. Bernardo Carrasco y Saavedra, en el año de 1688. Capítulo VII con 8 constituciones. Reeditado en Santiago en 1858.

28 El Concilio de Trento establece en Sesión VI, De residentia episcoprum, cap. 1, donde afirma: que la residencia es necesaria para que los obispos puedan cumplir con su deber; en el CIC 1917, Libro II, De las personas en el c. 338 fija la norma de Trento y en el CIC de 1983, en el Libro II, Parte II, sección II, c. 395, 1. que ha estado con la salud quebrantada y no ha podido ocuparse del todo, pero ha ido dando despacho a «los negocios corrientes que son muchos los de este obispado y de las iglesias sufragáneas...».

En la Relación de 1678 el arzobispo Liñán de Cisneros, registró que en 1677 «hicimos un viaje a través de lugares vastos y remotísimos... - agrega-, por muchos pueblos donde los arzobispos no habían alcanzado... que se trabajó en todos los sacramentos, confirmaciones»; y remata afirmando: «la ciudad de Lima es toda española». En la Relación de 1690 anota que «la enfermedad le ha impedido visitar su diócesis. Visitó el puerto del Callao con ocasión del terremoto y maremoto». Luego, comenta los efectos del sismo y maremoto, que causó daños en todos los monasterios del Callao. En el pueblo y en los campos problemas de alimentación y en enfermedades, temió una epidemia. Finaliza con una afirmación: «los peligros están en la tierra, y en el mar, porque por el mar han llegados los piratas, que con invasiones destruyen las ciudades y los lugares costeros».

\section{- Seminario}

Desde La Relación de Mogrovejo se tiene información del seminario, él registró: «donde están y entra mucha gente pobre en conformidad de lo proveído por el Sto. Concilio de Trento»; en el año 1651 el instituto tiene 24 estudiantes. La Compañía de Jesús por décadas regentó la administración del seminario. En relación con colegios: las órdenes son las que sostienen la educación; la Compañía de Jesús al año 1669 tiene dos colegios, San Felipe y San Martín.

\section{- Hospitales y hospicios}

En más de una Relación se registra la distribución de ellos y los destinatarios: el de San Andrés para todo tipo de hombres hispánicos, el de Santa Ana para indios e indias, el cuarto para curar a las mujeres hispánicas, aquel del Espíritu Santo para atender a personas marineras, el de San Pedro para los clérigos, otro para todo tipo de personas, y el de San Lázaro para los incurables de hombres y mujeres. De los hospicios señala que "son tres Casas hospicios para mujeres a modo de conventos con responsable y ayudantes para atender en la caridad a las jóvenes. Otro para mujeres que están separadas y vida deshonesta».

Del episcopado de Liñán, en la última Relación registra que los hospitales son doce. Bajo el Príncipe de los Apóstoles, San Pedro, con especial providencia y comisión de la congregación de San Felipe Neri; el de San Andrés, para los españoles enfermos, Santa María de la Caridad, anexo al Colegio Adolescentes; bajo el patrocinio de San Lázaro, orfanato, de la Virgen María de Atocha; navegantes, y para los incurables bajo la invocación de Santo Toribio, a cargo de los hermanos de San Juan de Dios. Aquel de los Incurables, Belén y Pedro de Alcántara están unidos por el presbítero Antonio de Ávila de Burgos.

\section{LAS DIÓCESIS PERIFÉRICAS: QUITO, AREQUIPA, SANTIAGO DE CHILE A TRAVÉS DE LAS RELACIONES DE VISITA AD LIMINA}

En los apartados anteriores se han ido instalando las fuentes y el método para desarrollar la hipótesis, que plantea: ¿qué factores permitieron un desarrollo sistemático y seguro de la instalación de la Iglesia en las diócesis periféricas, en contexto de misión? 
Si bien F. Braudel estudió el factor geografía física y geografía humana vinculado a la economía en el espacio del Mediterráneo; en este caso, la hipótesis plantea la relación del factor geográfico - físico y humano - con los atributos de la constitución eclesial católica y regulada con derecho propio, los que estuvieron mediatizados por el poder político que emanó del patronato español. En este escenario se hacen converger los tres elementos indicados: la geografía física y humana, la institucionalidad católica y el derecho patronal.

El apartado se desarrollará, en la lógica precedente, esto es, describir en tabla los contenidos documentales y personas, elaborar una síntesis de ellos en las Relaciones, y culminar con una exposición de contenidos transversales, entre ellas.

Las jurisdicciones de Quito, Arequipa y Santiago alcanzaron un ritmo alto de visita ad limina en dos siglos. La diócesis de Quito registra 13 preceptos ejecutados en todo el periodo; Santiago de Chile alcanzó una práctica altísima, 11 preceptos, siendo la de mayor frecuencia en el s. XVIII, 7 veces; $y$ Arequipa, estando más cercana a Lima, fue capaz de desarrollarse ya en el s. XVII en profundidad, alcanzó las 9 visitas. Solo dos diócesis de la provincia alcanzan 6 cumplimientos del precepto, las restantes tienen una frecuencia menor.

\subsection{Antecedentes documentales}

A continuación, en las Tablas 6, 7 y 8, siguiendo el método del apartado anterior, se presentan los antecedentes de la praxis de la visita ad limina de estas tres diócesis periféricas.

\subsection{Síntesis de los contenidos de las Relaciones entre la metrópolis y las diócesis periféricas}

En la columna de la izquierda de la Tabla 9 se instala la diócesis metropolitana como referencia temática. Los años que se anotan fijan una data de la Relación que registra información segura. Las otras columnas están las diócesis orientadas de norte a sur: Quito, Arequipa y Santiago de Chile. El orden temático se ordena por las reformas del Concilio de Trento.

3.3. Observaciones conclusivas acerca de los contenidos transversales en la práctica del precepto visita ad limina

Esta sección busca elaborar una síntesis sobre las distintas temáticas que han estructurado este apartado.

\section{Sobre procedimientos}

- En esta Provincia eclesiástica todos los obispos hicieron uso del procurador.

- El recurso de los testigos para probar el impedimento del obispo a viajar a Roma fue menor en las sufragáneas, que en la metrópolis.

\section{Sobre las estructuras eclesiales}

- Capítulo de la Catedral, seminario, parroquias y curatos: los datos son genéricos sobre estos contenidos, pero permiten formar una visión del desarrollo eclesial.

- De los conventos de frailes: es menor la información, empero, la Compañía de Jesús es loada y descrita en la dirección de colegios y seminarios.

- De los monasterios de monjas: registran información estadística, socio-religiosa, con matices sobre administración de ellos. En la provincia limeña se desarrolló un "red monacal femenina» de gran impacto en la Iglesia, en la construcción de la sociedad y en la instalación de una religiosidad específica, que tienen su origen en el carisma de la orden madre: franciscano, dominico, carmelita. La red sobresaliente es la de Santa Catalina de Siena: desde Quito, Lima, Arequipa y Tucumán.

TABLA 6

Antecedentes del nombramiento de los Procuradores de la iglesia de Quito

\begin{tabular}{|c|c|c|}
\hline Obispos de Quito (1545) & Datación & Procurador \\
\hline Ludovico López OSA & $1601(03 / 1603)$ & Único documento es el poder a Diego Torres, SJ. \\
\hline Fernando Arias de Ugarte & $1616(08 / 1617)$ & $\begin{array}{l}\text { El poder dado a Juan de Santander, SJ, fue sustituido por Francisco de Bobadilla, arcediano de Bilbao, en la } \\
\text { villa de Madrid, diócesis de Toledo, 23/12/1616. La fecha agosto de } 1617 \text { se registró en el reverso del poder } \\
\text { dado al padre J. Santander. }\end{array}$ \\
\hline Francisco Sotomayor OFM & $1628(01 / 1630)$ & Poder a Baltasar Mas SJ, quien es procurador general de la C. de Jesús en el nuevo Reino de Granada. \\
\hline Pedro de Oviedo OC & $1630(08 / 1633)$ & Poder a Francisco de Fuentes SJ, quien es procurador general del C. de Jesús para nueva Granada. \\
\hline Pedro de Oviedo OC & 1647 & Alonso de la Torre y Verna. Único documento fechado en el reverso 26 de marzo de 1647. \\
\hline Ildefonso de la Peña Montenegro & $1662(02 / 1664)$ & $\begin{array}{l}\text { Fr. Juan Martínez de Luzuriaga, agustino. Realizó la visita a Roma, a inicios del año de 1664, en el reverso del } \\
\text { poder se registró 13/02/1664. }\end{array}$ \\
\hline Ildefonso de la Peña & $1669(12 / 1670)$ & Fr. Fernando Colorado, procurador de los agustinos, en curia romana: diciembre de 1670. \\
\hline Sancho de Andrade y Figueroa & $\begin{array}{l}1699 \\
(14 / 04 / 1699)\end{array}$ & $\begin{array}{l}\text { Fr. Nicolás de León, franciscano. En los documentos aparece el uso de los testigos, quienes dan fe que } \\
\text { el obispo está de visita pastoral. Entre los testigos está el General Pedro de la Torre, Caballero Orden de } \\
\text { Calatrava y Juez primario de la ciudad. }\end{array}$ \\
\hline Luis Francisco Romero & $1720(04 / 1722)$ & $\begin{array}{l}\text { Juan Muxica SJ, procurador general para la provincia de Quito. Solicitud de prórroga para presentar estado de } \\
\text { la Iglesia. }\end{array}$ \\
\hline Juan Gómez de Navas y Frías & 1729 & Jerónimo Ramos SJ solicita prórroga. Únicos documentos: certificados de basílicas 6/12/1729. \\
\hline Andrés de Paredes y Armendaris & $1735(09 / 1740)$ & Tomás Nieto Polo y José María Arangerri procuradores de la Compañia de Jesús. \\
\hline Juan Nieto Polo del Aguila & 1753 & Ambrosio Batallas SJ y a Martín Egurbide, sustituido por Pedro Céspedes SJ, en Madrid en marzo de 1753. \\
\hline Juan Nieto Polo & $\begin{array}{l}1756 \text { Basílicas, } \\
\text { junio } 1756\end{array}$ & $\begin{array}{l}\text { Efectivamente Tomás Gijón y León, canónigo de la catedral. Cumplió con la visita en el 19/06/1756. Es } \\
\text { interesante observar que el canónigo tenia poder para ir a la beatificación de la Sierva de Dios Mariana de } \\
\text { Jesús, y en el poder indica que se le ha encomendado «otros asuntos... la visita ad limina». }\end{array}$ \\
\hline
\end{tabular}


TABLA 7

Antecedentes acerca del nombramiento de los Procuradores de la iglesia de Santiago de Chile

\begin{tabular}{|c|c|c|}
\hline Obispos de Santiago de Chile (1561) & Datación & Procuradores \\
\hline Juan Pérez de Espinoza OFM & $1609(03 / 1610)$ & $\begin{array}{l}\text { Tomás Pérez, de la iglesia de Santiago, sustituido en Madrid por Bartolomé Francés y } \\
\text { Marín Manso. }\end{array}$ \\
\hline Diego de Humanzoro OFM & $1666(09 / 1670)$ & Lorenzo Arrizábalo SJ. \\
\hline Diego de Humanzoro OFM & $1673(05 / 1676)$ & Diego de Rosales SJ. \\
\hline Bernardo Carrasco OP & $1682(04 / 1684)$ & Nicolás de Montoya OP. \\
\hline Francisco de la Puebla & $1701(01 / 1705$ & Ignacio de Alemán y Domingo Marín de la SJ. \\
\hline Luis Francisco Romero & $1708(02 / 1710)$ & Antonio de Covarrubias y Nicolás Kllefer de la SJ. \\
\hline L. Francisco Romero & $1713(09 / 1715)$ & Francisco Rosales y Fermín de Irisarri de la SJ. \\
\hline Alejo Fernando de Rojas & $1719(04 / 1721$ & $\begin{array}{l}\text { Miguel Núñez de Rojas, caballero de la Orden de Santiago; sustituido en Madrid por } \\
\text { Antonio Marimón, Deán de la iglesia de Girona, en 1720, y luego, en Francisco Abad María } \\
\text { de la Volpe. }\end{array}$ \\
\hline Juan González Melgarejo & $1746(02 / 1749)$ & $\begin{array}{l}\text { Ignacio Altamirano, delega en la Nunciatura de Madrid en el padre José de Lara; y luego } \\
\text { Simón Ramos, en Roma en enero } 1749 .\end{array}$ \\
\hline Manuel de Alday y Aspée & $1762(07 / 1763)$ & $\begin{array}{l}\text { Santiago Andrés SJ. La Relación diocesana no se encuentra en el A.S. Vaticano. Existe una } \\
\text { copia en Archivo del Arzobispado de Santiago, y una traducción del latín, en el Archivo } \\
\text { Nacional de Chile. }\end{array}$ \\
\hline Manuel de Alday y Aspée & $\begin{array}{l}\text { 1773. La documentación fue } \\
\text { pesquisada en A. Arz. de Santiago } \\
\text { de Chile }\end{array}$ & $\begin{array}{l}\text { Juan de Castillo, maestreescuela de la catedral, el poder está datado al } 17 \text { diciembre de } \\
1773 \text {, con el respectivo registro en la notaria eclesial. Se conserva la carta del obispo al } \\
\text { pontífice. }\end{array}$ \\
\hline
\end{tabular}

TABLA 8

Antecedentes acerca del nombramiento de los Procuradores de la iglesia de Arequipa

\begin{tabular}{|c|c|c|}
\hline Obispos de Arequipa (1577) & Datación & Procuradores \\
\hline Pedro de Villagómez & $1637(23 / 01 / 1639)$ & Rodrigo de Barrionuevo y Antonio Navarrete SJ. \\
\hline Fr. Gaspar de Villarroel, Agustino & $1657(01 / 10 / 1661)$ & El poder dado al Prior de San Agustín en Roma, único documento. \\
\hline Antonio de León & 1680 & Único documento datado en Nona Kalendas martii 1680 (21 febrero 1680). \\
\hline $\begin{array}{l}\text { Antonio de León de Arequipa y Andrés } \\
\text { de Navas de Nicaragua }\end{array}$ & $\begin{array}{c}1686 \\
(30 / 01 / 1688)\end{array}$ & $\begin{array}{l}\text { La carta al pontífice señala a los dos obispos, empero, de Nicaragua no se conserva otro } \\
\text { documento. Juan de Losada SJ. }\end{array}$ \\
\hline Antonio de León & $\begin{array}{c}1695 \\
(14 / 10 /\end{array}$ & $\begin{array}{l}\text { Se da poder al prepósito de la C. de Jesús y al procurador de la Compañía para España } \\
\text { en Roma, sin embargo, fueron sustituidos por Tirso González. Empero, el certificado de } \\
\text { basílicas señala que quien cumplió con el precepto fue Juan de Irigoyen SJ y la audiencia } \\
\text { en la Congregación, el } 14 \text { de febrero de } 1699 \text {. }\end{array}$ \\
\hline Juan de Cavero de Toledo & $\begin{array}{c}1731 \\
(14 / 05 / 1731)\end{array}$ & $\begin{array}{l}\text { Felipe del Castillo y Francisco Castañeda de la Compañía de Jesús. El certificado de las } \\
\text { basílicas confirma que F. del Castillo realizó la visita ad limina. Solicitó prórroga. }\end{array}$ \\
\hline Juan Cavero & 1732 & Bartolomé Bianchieri, cumplió presentando la Relación, el 30 de junio de 1732. \\
\hline Juan de Cavero & $\begin{array}{c}1734 \\
(02 / 04 / 1634)\end{array}$ & Procurador Bartolomé Bianchieri, presbítero de la diócesis de Virtimiglia. \\
\hline Jacinto & 1757 & $\begin{array}{l}\text { Único documento es un texto brevísimo, datado el } 3 \text { febrero de 1759. Informa de la visita } \\
\text { general a la diócesis. }\end{array}$ \\
\hline
\end{tabular}

\section{Sobre las reformas del Concilio de Trento}

- La residencia del obispo: el prelado al momento de ser ordenado obispo juró hacer personalmente la visita ad limina cada 10 años, para dar cuenta de su oficio pastoral. Se han señalado las razones porque no puede realizarla personalmente. En esas razones surge de manera subyacente la razón más importante: cumplir con la residencia. Varios de ellos señalan que por las largas distancias - hasta cinco años ida-regreso- y tiempo que requiere no pueden abandonar la diócesis, por el mandato de residencia del Concilio de Trento, y, porque el Rey lo impide, por la misma razón de la residencia episcopal. Él la cumple fielmente. ${ }^{29}$

29 La descripción más detallada del viaje a Roma la hizo el arzobispo de Sucre, Cristóforo de Castilla, en la Relación de 1681, al anotar: «Desde Arica al Puerto Callao, desde Callao a Panamá, desde Panamá a Puerto
- La visita pastoral: la práctica de la visita pastoral a la diócesis es uno de los contenidos más relevantes de la reforma trentina. Esta acción pastoral en estas zonas fue orientada en clave o con carácter misionero. Al referirse a ella los obispos señalan el tiempo que les ha tomado recorrer toda la jurisdicción - de tres a cuatro años - que ha confirmado cientos de personas y predicado. Un asunto que debe Ilamar la atención, que señalan varios obispos: desde hace muchos años que no pasaba un obispo.

Velo, desde P. Velo a Cartagena, desde Cartagena a La Habana, desde La Habana a España, desde España a Roma». Y finaliza «debe agregarse los asuntos climáticos y peligros de los piratas ingleses, franceses y holandeses». Cf. ASV, Relación diocesana del Obispo de Sucre, C. de Castilla (julio de 1681), Caja n. 649. 
TABLA 9

Síntesis comparada del estado de las iglesias periféricas y la metropolitana

\begin{tabular}{|c|c|c|c|}
\hline $\begin{array}{l}\text { Lima Arz. Villagómez }{ }^{30} \\
\text { 1642-1651-1660-(1669) }\end{array}$ & $\begin{array}{l}\text { Quito } \\
\text { 1633-1669 }\end{array}$ & $\begin{array}{c}\text { Arequipa } \\
1680-1686\end{array}$ & $\begin{array}{l}\text { Santiago Chile } \\
1666-1682-1762\end{array}$ \\
\hline $\begin{array}{l}\text { Capítulo y cargos: } 5 \text { dignidades, canónicos } \\
\text { 10, } 6 \text { porcioneros, sacristanes 2, } 1 \text { corista; } \\
1 \text { ceremoniero, músicos y ecónomo } \\
\text { fábrica, } 1 \text { notario. }\end{array}$ & $\begin{array}{l}\text { En } 1633 \text { se tiene } 5 \text { dignidades y } 5 \\
\text { canónicos, } 4 \text { racioneros y } 2 \text { párrocos. }\end{array}$ & $\begin{array}{l}\text { En } 1680 \text { se indican } 5 \text { dignidades: } \\
\text { canónico doctoral, } 2 \text { racioneros, } \\
\text { capellanes de coro, sacristán mayor. }\end{array}$ & $\begin{array}{l}\text { En } 1666 \text { se indican } 5 \text { dignidades y } 5 \\
\text { canónicos. Datos geográficos. }\end{array}$ \\
\hline $\begin{array}{l}\text { Parroquias: al año 1660: en Lima } 5 \text { y } \\
180 \text { parroquias y curatos. Con título } 80 \\
\text { clérigos regulares, el resto seculares. Total } \\
\text { sacerdotes } 200 \text {. }\end{array}$ & $\begin{array}{l}\text { Parroquias } 6 \text { en ciudad; } 102 \text { villas, } 20 \\
\text { de españoles con párrocos y vicarios. }\end{array}$ & $\begin{array}{l}\text { Parroquias: } 2 \text { para españoles, } 3 \text { para } \\
\text { indios. En diócesis hay } 36 \text { parroquias } \\
\text { clérigo secular y } 16 \text { de regulares. }\end{array}$ & $\begin{array}{l}\text { Parroquias: a } 1666 \text { hay } 30 \text { parroquias, a } \\
1701 \text { ascienden a } 43 \text { y, en } 1762 \text { a } 50 .\end{array}$ \\
\hline $\begin{array}{l}\text { Seminarios: en } 1599 \text { arzobispo Mogrovejo } \\
\text { ofrece breve informe del seminario. } \\
\text { El procurador D. Torres señala que el } \\
\text { seminario es dirigido por la Cía. de Jesús. } \\
\text { En el año } 1651 \text { tiene } 24 \text { estudiantes. }\end{array}$ & $\begin{array}{l}\text { El seminario en } 1633 \text { tiene } 20 \\
\text { estudiantes y está dirigido por la Cía. } \\
\text { Jesús. Hacia 1669: dirigido por Cía. } \\
\text { Jesús, da grado de magíster y doctor. } \\
\text { En } 1669 \text { se dan grados de magister } \\
\text { y doctor. }\end{array}$ & $\begin{array}{l}\text { Hacia } 1637 \text { se enseña arte y gramática. }{ }^{31} \\
\text { En } 1680 \text { hay } 14 \text { jóvenes estudian } \\
\text { gramática, música para las ceremonias } \\
\text { del oficio divino. }\end{array}$ & $\begin{array}{l}\text { El seminario hacia } 1701 \text { tiene } 7 \\
\text { estudiantes. En } 1762 \text { hay dos: } \\
1 \text { sometido al Ordinario con } 16 \\
\text { estudiantes; el otro de la Cía. Jesús, con } \\
40 \text { estudiantes. }\end{array}$ \\
\hline $\begin{array}{l}\text { Sínodos y concilios: } \\
\text { Datos desde el arzobispo Mogrovejo. }\end{array}$ & & $\begin{array}{l}\text { En } 1638 \text { celebró sínodo el arzobispo } \\
\text { Villagómez. }\end{array}$ & $\begin{array}{l}\text { Cuatro sínodos: 1626, 1670, 1688, } 1763 . \\
\text { Las normas orientan las reformas }\end{array}$ \\
\hline $\begin{array}{l}\text { Hospitales - Hospicios: } \\
\text { Hospitales: San Juan de Dios, San Pedro } \\
\text { para clero, para navegantes, para indios. } \\
\text { Hospicio: de Monserrat, S. Francisco de } \\
\text { Paula, para huérfanos. }\end{array}$ & & $\begin{array}{l}\text { Un hospital para españoles e indios, a } \\
\text { cargo del capítulo secular. }\end{array}$ & $\begin{array}{l}\text { Hospitales/ hospicios en principales } \\
\text { ciudades. }\end{array}$ \\
\hline $\begin{array}{l}\text { Monasterios/conventos } \\
\text { Hombres: S. Domingo 2, S. Agustín 2, S. } \\
\text { Mercedarios } 1 . \\
\text { San Bernardo existe aún al año } 1692 . \\
\text { Mujeres: Encarnación Señor, } 250 \text { personas, } \\
\text { I. Concepción, 280; S. Trinidad, 101; San } \\
\text { José, 82; S. Clara, 282; } \\
\text { Catalina Siena, 74; S. M. Prado, 33; } \\
\text { Carmelitas, } 20 .\end{array}$ & $\begin{array}{l}\text { Hombres: dominicos, franciscanos, } \\
\text { agustinos, mercedarios, Cía., y } \\
\text { descalzos dominicos y franciscanos. } \\
\text { Mujeres: } 3 \text { en } 1669 \text { el de S. Catalina } \\
\text { de Siena e indica muchas mujeres. }\end{array}$ & $\begin{array}{l}\text { Hombres: al año 1637: dominicos, } \\
\text { franciscanos, agustinos, mercedarios, y } \\
\text { Compañía. } \\
\text { Mujeres: en } 1681 \text { el monasterio Sta. } \\
\text { Catalina educa a } 75 \text { señoritas y alberga } \\
\text { más de } 100 \text { religiosas. }\end{array}$ & $\begin{array}{l}\text { Hombres: en } 1701 \text { dominicos, } \\
\text { franciscanos, agustinos, mercedarios y } \\
\text { Cía. Total } 37 \text { casas y } 382 \text { religiosos. } \\
\text { Mujeres: en } 1762 \text { hay 6: Agustinas, } \\
\text { Clarisas, S. Clara Capuchinas, Descalzas } \\
\text { S. Teresa, y Sta. Rosa de Lima. }\end{array}$ \\
\hline $\begin{array}{l}\text { Cofradías: para hospicios. No se registran } \\
\text { las de carácter religioso. }\end{array}$ & & $\begin{array}{l}\text { Del Santísimo Sacramento, de las Almas, } \\
\text { de la Asunción, y San Bartolomé. }\end{array}$ & $\begin{array}{l}\text { En } 1762 \text { obispo Alday registra: del Smo. } \\
\text { Sacramento y de la Doctrina Cristiana, } \\
\text { Ánimas }\end{array}$ \\
\hline $\begin{array}{l}\text { Visita Pastoral: práctica cumplida más de } \\
\text { una vez, por los distintos arzobispos hasta } \\
\text { Liñán de Cisneros a fines del s. XVII }\end{array}$ & $\begin{array}{l}\text { Realizada: en } 1633,1669,1696 \text { y } \\
1751 \text { (testigos ofrecen datos visita } \\
\text { pastoral). }\end{array}$ & $\begin{array}{l}\text { En } 1635 \text { inició visita por } 22 \text { meses. Se } \\
\text { informa en } 1686 \text { que la visita no se } \\
\text { hacía desde hace } 44 \text { años }\end{array}$ & $\begin{array}{l}\text { La visita se ha realizado desde siempre. } \\
\text { Afirma: fue un instrumento de reforma. }\end{array}$ \\
\hline $\begin{array}{l}\text { Doctrinas o Curatos: Más de } 100 \\
\text { doctrinas, muchas de frailes, hay más de } \\
120 \text { clérigos. } \\
\text { Hacia } 1650 \text { el tema de la idolatría persiste. }\end{array}$ & $\begin{array}{l}\text { Más de } 80 \text { doctrinas, } 9 \text { asistidas } \\
\text { por curas seculares, el resto son } \\
\text { religiosos, y una asistida por Cía. }\end{array}$ & $\begin{array}{l}\text { Los indios se describen en 1759: } \\
\text { humildes, pobres, dóciles, inclinados a } \\
\text { la embriagues. }\end{array}$ & $\begin{array}{l}\text { En Santiago a 1666, la Relación constata } \\
\text { abusos a los indios: «una voz que clama } \\
\text { al cielo»; todos hablan español. }\end{array}$ \\
\hline $\begin{array}{l}\text { Excepcionales: } \\
\text { Las tres ermitas: Copacabana, del Socorro } \\
\text { y Las Cabezas. } \\
\text { Terremoto en } 1678 \text { devastador. } \\
\text { Concilios provinciales: } 1583,1591,1601 . \\
\text { Universidad Real de San Marcos. }\end{array}$ & & $\begin{array}{l}\text { En el episcopado de Antonio de León } \\
(1680-1700) \text { se observa consolidada la } \\
\text { Iglesia. }\end{array}$ & $\begin{array}{l}\text { Carencias de formación del clero. } \\
\text { Terremotos } 1647 \text { y } 1700 \text { son } \\
\text { devastadores. }\end{array}$ \\
\hline Solicitudes: & $\begin{array}{l}\text { Facultades para dispensas, } \\
\text { matrimonial. }\end{array}$ & & Facultades para dispensas, matrimonial. \\
\hline
\end{tabular}

30 La referencia al arzobispo Villagómez da seguridad del grado de desarrollo de la diócesis de Lima, gobernó por 27 años. Él fue trasladado desde Arequipa en 1640. Es un prelado que ha trabajado en la zona por mucho tiempo. Los datos son de preferencia de la 3 a visita, los que reflejan la estructura eclesial ya madura.

31 En las Relaciones de Arequipa no se hace referencia al seminario. No obstante, se tiene constancia que este instituto fue fundado en 1622 , bajo el episcopado de Pedro Perea. El de Quito en 1569; Santiago de Chile en 1584; Tucumán en 1597. Cf. Vergara Javier. 2005. Datos y fuentes para el estudio de los seminarios conciliares en Hispanoamérica: 1563-1800. En AHIg. 14. Navarra: pág. 247 


\section{CONCLUSIONES}

Las conclusiones articulan los principales ejes desde los cuales se ha elaborado este estudio: las fuentes archivísticas, la recepción del Concilio de Trento y la relación diócesis metropolitana-diócesis sufragáneas. Este último contenido se aborda con el concepto centro-periferia. El objetivo final del trabajo es aportar a la comprensión de la instalación y maduración de las comunidades eclesiales en la provincia eclesiástica limeña, en el periodo hispánico.

\subsection{La práctica de visita ad limina y los contenidos de las Relaciones diocesanas}

\section{Aspectos conclusivos generales}

- La referencia que Mogrovejo hace que «ha cumplido con el precepto de visita ad limina» citando años antes de la bula de 1585, permite suponer que él conoció la práctica de peregrinar a los sepulcros de los apóstoles, como tradición eclesial en la forma medieval. Desde esta perspectiva adquiere sentido la súplica de Mogrovejo, en la cual solicita «hacerla por procurador anualmente, mientras él esté vivo». Este es un asunto temático importante.

- Al revisar los distintos legajos se aprecia que el esfuerzo de los obispos va dirigido a «cumplir con el precepto de la Visita». La documentación arroja abundantes testimonios que sostienen esta hipótesis. El registro más temprano de esta declaración ya se tiene en la Relación de Mogrovejo, en el texto de 1599, indica: que ha dado poderes, para que en su nombre hagan las visitas a los «umbrales de Pedro y Paulo, todos los años».

- Esta aproximación a las fuentes orienta en la comprensión eclesiológica de la dinámica del proceso, es decir: que la relación Pedro-Apóstol no fue tensional en el manejo de este precepto; tampoco las normas patronales fueron obstáculo para su cumplimiento; y la institución del procurador, logró más que la sola representación legal del obispo, pues el procurador era un conocedor de las comunidades eclesiales.

- Por último, las Relaciones, aun en aquellas muy breves, reflejan la recepción del C. de Trento, ellas constatan los esfuerzos de los prelados por implementar el Concilio: cumplen con la residencia episcopal y realizan la visita pastoral, fundan el seminario.

\section{Aspectos conclusivos particulares}

- La datación de las fuentes: al fijar con mayor precisión estas fuentes se ha logrado mejorar los elencos que se han elaborado hasta el momento, a guisa de ejemplo: se definió que el proceso de Mogrovejo/procurador -1599-1603- es uno solo; se ha resuelto el cumplimiento de las visita ad limina de F. Arias de Ugarte en Arequipa, precisando dos preceptos cumplidos. Los datos en la Relación de 1603 sobre Truxillos, la cual es considerada en el texto no como diócesis sino como una villa, confirma que esta jurisdicción fue canónicamente erigida en 1616, pues había sido creada 1577.

- Las fuentes al estudiarlas en clave eclesial poseen solidez: esta afirmación se prueba al individualizar los aspectos relacionados con la estructura general y particular de la Iglesia, con la administración y con las expresiones religiosas de la comunidad. Por ejemplo: Mogrovejo señala que hay tres ermitas en el confín de la ciudad, dedicadas a la Nuestra Señora de Copacabana, del Socorro y de Los Remedios. Este contenido de los tres santuarios marianos indica lo siguiente: la devoción de Copacabana se asentó en la arquidiócesis tempranamente, posteriormente se transformó en el santuario principal de la diócesis de Cochabamba y luego patrona de Bolivia, las otras dos devociones dieron origen a parroquias.

- Se ofrecen detalles de las primeras fundaciones religiosas femeninas de procedencia española/criolla: en especial aquellas del obispo Loayza y la franciscana de Mogrovejo, bajo la invocación de la Nuestra Señora de Copacabana, que llegan hasta el presente.

\subsection{La recepción del Concilio de Trento y las Leyes patronales}

El Libro I de la Leyes de Indias está estructurado en XXIV títulos y sus respectivas normas cubren todo lo ordenado por Trento, desde los asuntos de las iglesias catedrales hasta los libros que se imprimen y pasan a las Indias.

- Residencia episcopal: esta norma está subyacente en la expresión del obispo, con la cual se justifica no poder realizar la visita ad limina personalmente. Esta excusa no se puede interpretar como: que están impedidos por las normas patronales, pues no se hace referencia a una prohibición, sino porque las leyes patronales mandaban resguardar el Concilio de Trento. En Libro I, Tít. VII, Ley XXXVI, se afirma:32 "Los arzobispos y obispos de nuestras Indias están obligados a residir en sus prelacías conforme a derecho y al santo Concilio de Trento, y a Nos por nuestra regalía, y como patrón universal de todas las iglesias toca el cuidado de proveer que se guarde y ejecute».

- Visita a la diócesis: las Leyes orientan las tareas del ministerio episcopal: visitar la diócesis en el Lib. I, Tít. VII, Ley XXIV. Una nota a subrayar en estos textos se ofrece al describir los requerimientos para quienes podrían ser visitadores, cuando el obispo no puede hacerla personalmente.

- Desarrollo parroquial y curatos: el desarrollo parroquial es un contenido que requiere más investigación cuantitativa y cualitativa. Algunas razones: es difícil precisar el tránsito desde la doctrina hacia la parroquia y establecer el tiempo que tomó ese tránsito o el ciclo misionero en el doctrina y parroquia. Esta línea de estudio se podría vincular a la práctica de la visita pastoral. $^{33}$

- Seminario y colegios: aquellas normas que se refieren a los seminarios y colegios, se sitúan en el Título XXIII, con quince normas particulares. En las Relaciones no

32 Recopilación de Leyes de los Reinos de las Indias, mandadas imprimir y publicar por la Majestad Católica del Rey don Carlos II. Madrid 1841. Libro Primero, Ley XXXVI, Tomo Primero, pág. 43.

33 Los escasos estudios de las visitas ad limina de Lima en Maldavsky 2002, por ejemplo, se han leído con cierto margen de error el número de parroquias y otras instituciones eclesiales. 
hay información profusa sobre estos institutos. En algunas Relaciones registran solo su existencia.

- Las cofradías de la Doctrina Cristiana y del Santísimo Sacramento: hay notable ausencia de estas dos instituciones, que si bien tienen orígenes antiguos, fue Trento que las fijó e impulsó su desarrollo. Los obispos ofrecen pocos detalles de ellas.

\subsection{Sobre la dinámica eclesial centro-periferia y periferia-centro}

El rol articulador de la metrópolis limeña: la relación centro-periferia

- El rol articulador de Lima fue de excepción: desde la creación del arzobispado de Lima en 1546 hasta la creación del arzobispado de Sucre en 1609, se aprecia una primera fase. En estos cerca de sesenta años se consolidaron dos espacios geográficos: aquel del sector occidental del Perú con las diócesis de Guamanga y Truxillos, que se agregan a la estructura ya dada con Cusco y Arequipa; y el de la meseta andina que abarca desde La Paz, Santa Cruz y Sucre y se prolonga - geopolíticamente- hasta Paraguay, pasando por Tucumán. En este espacio emerge una comunidad eclesial que se desarrolla por el Atlántico, con dificultades.

- Rol articulador de Lima por el Pacífico: las diócesis de Panamá y Quito, y Santiago y Concepción de Chile seguirán siendo sufragáneas de Lima hasta el siglo XIX. En 1840 Santiago fue creado arzobispado y en 1848 Quito; el desmembramiento de Panamá será más lento aún, recién en el año 1900 será sufragánea de Cartagena de Indias.

- Las diócesis en el espacio de la provincia de Lima: las Relaciones de las sufragáneas creadas ya en el s. del XVI -Cusco, Huamanga, Truxillos, Arequipa- se desarrollan a un ritmo más lento, con excepción de Arequipa que posee un ritmo de mayor celeridad, a pesar de la postergación que tuvo la instalación misma de la diócesis hasta adentrado el s. XVII. Destaca la maduración de Arequipa en todos los ámbitos; el caso más difícil de evaluar es el estancamiento de la diócesis de Huamanga, Truxillos y Cusco, que incluso esta última teniendo Universidad su desarrollo y maduración fue frágil.

La maduración de las diócesis periféricas: la relación periferia-centro

En los siguientes argumentos se articulan los factores geográficos - físico y humano- y los atributos de la constitución eclesiástica - autonomía episcopal y colegialidaden las diócesis de Quito, Arequipa y Santiago de Chile, para observar como ellos incidieron en el desarrollo y maduración cualitativa.

\section{- La geografía física y humana}

Los obispos de estas diócesis dejan constancia en las Relaciones de las limitaciones y cualidades de sus territorios y de sus gentes. Registran descripciones, juicios. Referente a lo geográfico afirman: áspera, difícil de visitar, distancias grandes; y sobre los pueblos originarios: ellos viven en las montañas y hablan muchas lenguas. La población es dividida en españoles, etíopes e indios, "toda Lima es española».

El factor espacio geográfico y humano en el desarrollo de la estructura eclesial se constituyó en un factor clave. La creación del arzobispado de Sucre - desde La Paz hasta Paraguay - o la permanencia de Quito hasta 1848 como sufragánea de Lima, son decisiones donde el factor geográfico fue importante. Es posible que la inestabilidad de Panamá y sin una metrópolis definitiva obedezca al mismo factor. Los prelados de Panamá la han defendido - hasta el presentecomo la primera iglesia en tierra firme. Esta «situación de tierra firme» la vincula hacia la metrópolis limeña.

El peso que tuvo el cambio desde un episcopado español hacia otro de origen criollo fue decisivo para generar la unidad geográfica y humana, en estas comunidades eclesiales. ${ }^{34}$ El caso único es el de Santiago de Chile: el episcopado cambió de manera significativa durante el s. XVIII. La totalidad de los obispos pertenecieron al clero secular; y si se ausculta la procedencia de origen el cambio es más evidente. De los diez obispos solo dos proceden de España y los restantes son tres de Perú, dos de Chile, uno de Paraguay y uno de Bolivia. El obispo criollo Manuel de Alday y Aspée, nacido en Concepción, regentó la diócesis por 33 años. Incluso asistió al concilio limeño de 1774. Cumplió con el precepto visita ad limina dos veces, y la Relación del estado de la diócesis de Santiago -1762-, constituye un texto extenso y completo; realizó la visita pastoral a toda la diócesis y celebró el VI sínodo diocesano, en 1763.

Otro ministerio episcopal en la línea con la argumentación anterior fue la de Fernando Arias de Ugarte, nacido en Bogotá en 1561. Este obispo inició su peregrinación episcopal en Quito en 1613, pasó a Santa Fe en 1616... luego, a Sucre en 1624 y culmina en Lima 1628-1638. Los 27 años de ministerio episcopal tienen un resultado pastoral interesante. Cumplió con el precepto de visita ad limina en Quito, Santa $\mathrm{Fe}^{35}$ y dos veces en Lima. Las Relaciones sobre el estado de la Iglesia de Santa Fe del año 1620 y la de Lima de 1637 son muy completas.

Empero, sería un error afirmar que la sola procedencia criolla del obispo logró un ministerio episcopal fructífero. Un caso que reúne notas tanto del perfil político como eclesiástico fue el de Melchor de Liñán y Cisneros, nacido en Madrid en el año 1609, quien peregrina por un proceso similar a F. Arias, y, con éxito pastoral, al modo de aquel de Manuel de Alday de Santiago de Chile. Inició su ministerio episcopal en Santa Marta en 1664, pasó a Popayán en 1668; luego a Sucre en 1672 y a Lima en 1677-1708: Total 44 años de episcopado.

Desde esta perspectiva el episcopado latinoamericano del periodo hispánico asumió el carácter fundacional de estas comunidades, lo hicieron desde la recepción de las reformas del C. de Trento y se articularon con libertad en relación con la Corona.

34 En la historiografía sobre el clero latinoamericano Paulino Castañeda Delgado destaca por la larga trayectoria investigativa. Un texto de síntesis orientado a la jerarquía de la Iglesia iberoamericana, que incluye el aporte historiográfico, el investigador Castañeda lo presentó en el Simposio convocado por el Vaticano en 1992: Cf. Castañeda Delgado 1992.

35 ASV., Relaciones diocesanas arzobispo de Santa Fe, F. Arias de Ugarte (1620), caja n.o 333. 


\section{- El carácter fraternal de los obispos como respuesta a las distancias}

Se ha expuesto antes que en la Relación de Mogrovejo/ Procurador -1599-1603- ya algunos obispos sufragáneos de Lima cumplieron con la visita ad Limina aprovechando aquella del arzobispo Mogrovejo. ${ }^{36}$ Interesante particularidad, Mogrovejo incluyó en la Relación aspectos de las sufragáneas y de la diócesis de Cartagena de Indias. El obispo cartagenero aprovechó la oportunidad del paso del procurador hacia Roma. Otros obispos incorporan en la Relación aspectos de la diócesis desde donde fueron trasladados. ${ }^{37}$

Desde la clave de Braudel - geografía humana- se puede definir el traslado del obispo como un asunto de política eclesiástica y no solo reducirlo a poder. El estudio subraya el conocimiento y los resultados pastorales que se obtienen de la peregrinación de los traslados, sea sobre la visión antropológica, social, canónica y pastoral de sus comunidades y sobre todo el carácter colegial de ellos. Cada uno orientó su labor hacia lo que va evaluando: Arias la idolatría en Bogotá y luego en Lima; Villagómez las familias religiosas femeninas tanto en su incremento como en la vida interna y externa de ellas, y Liñán y Cisneros el terremoto fue su principal preocupación para reconstruir iglesias, creó terceras órdenes, reformó los monasterios e incrementó los hospitales. Articula la beneficencia con las familias más ricas.

- La lectura de la Bula In Cena Dominus, en Jueves Santo 38

De este instrumento pastoral de control ético se tiene poca información en las Relaciones. Solo el obispo franciscano Diego de Humanzaro, de Santiago de Chile lo cita en la aquella de 1666 .

- El rol de los Sínodos en la construcción de la comunidad eclesial

Santiago de Chile es un caso excepcional. Si bien son extensamente conocidos los concilios provinciales III de Lima y III de México, en el año 1583 y 1585 respectivamente, por la influencia que tuvieron en sus respectivas provincias; la tradición sinodal no es menor. Los sínodos celebrados en el periodo hispánico fueron 57.

Una forma de cerrar este estudio es articularlo con las Novedades y Solicitudes que los obispos planteaban a Roma. Como materia relevante, prevalecen las facultades para dispensar en materia matrimonial: fue un contenido que emerge en las Relaciones. El obispo de Truxillos, Juan de la Calle, en la Relación de 1669 y el de Quito en

36 En la Relación de Mogrovejo de 1603, se adjuntaron breves Relaciones de los obispos de Cusco, Quito, Charcas o de La Plata, Popayán, Panamá y Cartagena de Indias.

37 Es el caso del obispo de Panamá Antonio de León que fue trasladado a Arequipa. En su Relación de 1680, ya en Arequipa, incorpora una breve descripción sobre la diócesis de Panamá. También lo hizo el arzobispo Pedro de Villagómez al referirse a Arequipa, su sede anterior. Cf. ASV., Relaciones diocesanas del obispo de Panamá, Antonio de León (1680), caja n. 616.

38 Uno de los casos más peculiares son las instrucciones que da en el Auto de Visita el Obispo Fr. Diego de Humanzoro, de Santiago de Chile, del 26 de diciembre de 1663, en el cual manda que los curas o doctrineros deben tener los textos de la Bula In Cena Dominus, junto a Concilio de Trento, los Concilios Provinciales de Lima de 1567 y 1583, y el Catecismo del Señor Papa Pío Quinto. Cf. Falch Frey 1986: 245-247.
1722, solicitaron las facultades para dispensar en materias matrimoniales.

La preocupación de los obispos por los asuntos prácticos en derecho matrimonial, es un surco a investigar, sobre todo si se orienta a precisar la evolución del «privilegio paulino», en circunstancia de regiones de misión, incluso ya en la época se dieron soluciones canónicas universales. Con la expansión de la Iglesia desde el siglo XV -hacia Oriente y América Latina - el Derecho canónico en materia matrimonial precisó la aplicación del «privilegio paulino» a las nuevas circunstancias. Así lo reconoce la Congregación para la Doctrina de la Fe, Normas para realizar el proceso para la disolución del vínculo matrimonial en Favor de la Fe, del 30 de abril del 2001. ${ }^{39}$

\section{FUENTES}

Archivo Secreto Vaticano, Relaciones Diocesanas en Fondo Congregación Concilio

Provincia de Lima:

- Arequipa, Caja 75.

- Cusco, Caja 285.

- Guamanga, Caja n. 379.

- Imperial o Concepción de Chile, Caja n. ${ }^{\circ} 248$.

- Lima, Caja n. ${ }^{\circ} 450$.

- Nicaragua, Caja n. 576.

- Panamá, Caja n. ${ }^{\circ} 616$.

- Popayán, Caja n. 655.

- Quito, Caja n. ${ }^{\circ} 672$.

- Santiago de Chile, Caja n. ${ }^{\circ} 411$.

- Truxillo, Caja n. ${ }^{\circ} 821$.

Provincia de Sucre:

- Buenos Aires, Caja 135.

- La Paz, Caja n. ${ }^{\circ} 610$.

- Paraguay, Caja n. 619.

- Santa Cruz, Caja n. 277.

- Sucre, Caja n. 649.

- Tucumán, Caja n. 823.

Documentos impresos:

Concilio Ecuménico de Trento (Traducido por Ignacio López de Ayala). 1848. Paris. 9a Edición

Recopilación de las Leyes de los Reinos de las Indias. 1841. Tomo I, Madrid.

Código de Derecho Canónico (Texto latino y versión castellana). 1945. Salamanca. Documentos VI, VII.VIII.

\section{BiBLIOGRAFÍA}

Araya Rivera, Hugo. 1976. Notas biográficas de religiosos franciscanos de Chile. Santiago de Chile: Alfabeta Impr.

Braudel, Fernand. 1981. El Mediterráneo y el mundo mediterráneo en la época de Felipe II. Dos volúmenes. México: Fondo Cultura Económica.

Camus Ibacache, Misael. 1994. «La visita ad limina desde las iglesias latinoamericanas 1585-1800». Hispania Sacra 93: 159-190.

39 El señalado texto de la Congregación en el párrafo Cuarto, cita: "A esto se refieren especialmente las Constituciones Apostólicas de Paulo III Altitudo, del 1 de junio de 1537; de San Pío V, Romani Pontifices, del 2 de agosto de 1571; de Gregorio XIII, Populis, del 25 de enero de 1585, que estuvieron vigentes en los territorios para los que se habían dado hasta la promulgación del Código del año 1917». Cf. CIC 1917, Documentos. 
Cárcel Ortí, María M. 2002. "Las Visitas ad limina: propuesta de edición». En Les Chemins de Rome. Les Visites ad limina à l'époque moderne dans l'Éurope Meridionale et le Monde HispanoAmericain, editado por Philippe Boutry y Bernard Vincent, 5-37. Collection de L'École Francaise de Rome 293. Roma: École française de Rome.

Castañeda Delgado, Paulino. 1992. "La jerarquía de la iglesia en Iberoamérica». En Historia de la Evangelización de América. Actas Simposio Internacional, 11-14 de mayo, 77-97. Ciudad del Vaticano: Librería Editrice Vaticana.

Donoso Vivanco, Justo. 1855. Diccionario teológico, canónico, jurídico. Tomo I y II. Valparaíso.

Duque Alcaide, Elisa. 2011. «Iglesia y Estado en América: de los concilios provinciales del siglo XVIII a los celebrados en el siglo XIX». En Tradición y Reforma en la Iglesia Hispanoamericana 1750-1840, 325-348. Puebla: ICSyH-BUAP, IISUE-UNAM, Centro de Estudios Bicentenario.

Falch Frey, Jorge. 1986. "Carta Pastoral y Autos de Gobierno de Fr. Diego de Humanzoro, obispo de Santiago de Chile». Anuario Historia de la Iglesia en Chile 4: 245-260
Hera, Alberto de la. 1992. "El regalismo indiano». Ius Canonicum XXXII, 64: 411-437.

Hernáez, Francisco. 1872. Colección de Bulas, Breves y otros Documentos relativos a la Iglesia de América y Filipinas. Bruselas, dos volúmenes.

Leonardi, C. (dir.) 1998. II Grande libro dei Santi. Dizionario enciclopedico. Turín: San Paolo Edizioni.

Maldavsky, Aliocha. 2002, "Les visites ad limina des Archevêques de Lima au XVV siècle». En Les Chemins de Rome. Les Visites ad limina à l'époque moderne dans l'Éurope Meridionale et le Monde Hispano-Americain, editado por Philippe Boutry y Bernard Vincent, 213-234. Collection de L'École Francaise de Rome 293. Roma: École française de Rome.

Vergara, Javier. 2005. «Datos y fuentes para el estudio de los seminarios conciliares en Hispanoamérica: 1563-1800». Anuario de Historia de la Iglesia 14: 239-300.

Stieger, Reinaldo y Agustín Roberts. 1987. "Los Cistercienses en América Latina». En Los Cistercienses, Ideales y Realidad, Louis Lekai, 577-608. Barcelona: Herder. 